Article

\title{
Acoustic Comfort as a Salutogenic Resource in Learning Environments-A Proposal for the Design of a System to Improve the Acoustic Quality of Classrooms
}

\author{
Antonio Laurìa $₫$, Simone Secchi $* \mathbb{C}$ and Luigi Vessella $₫$ \\ Department of Architecture, University of Florence, 50121 Firenze, Italy; antonio.lauria@unifi.it (A.L.); \\ luigi.vessella@unifi.it (L.V.) \\ * Correspondence: simone.secchi@unifi.it; Tel.: +39-339-4831597
}

Received: 31 October 2020; Accepted: 20 November 2020; Published: 22 November 2020

\begin{abstract}
This article addresses the topic of environmental comfort from a salutogenic and pedagogical point of view. It begins by presenting a wide framework aimed at describing the complexity and specificity of the acoustic issue and the need to integrate decibel-based metrics with knowledge and reflections which are inherent to non-measurable factors. The article then focuses its attention on educational spaces and presents the results of an investigation carried out in 52 classrooms of 19 primary schools in Florence. From this research and keeping in mind the current Italian legislation, the following results are deduced: (1) the layout of a typical classroom, (2) the average reverberation time and (3) the sound-absorbing surface required to improve the acoustic quality of the typical classroom with polystyrene fibre panels. Subsequently, after having briefly described the more appropriate typology of sound-absorbing solutions, a system for the acoustic correction of classrooms is presented. This system is composed of two parts. The first part is fixed and its realisation is entrusted to specialised personnel; the second, based on the concept of personalisation and transformation of the educational space, is modifiable through time and designed and applied by the students themselves.
\end{abstract}

Keywords: wellbeing; salutogenesis; indoor environmental quality; acoustic quality; reverberation time; healthy learning; classroom

\section{Introduction}

\subsection{Measurable and Non-Measurable Factors of Environmental Comfort}

Although ISO 28,802 regulations [1] encourage the study of environmental comfort through the consideration of both the material measures of the space and the subjective responses of the inhabitants, the indoor environmental quality (IEQ) is mostly analysed in terms of "measurable" material factors (indoor air quality, thermal, acoustic and lighting parameters).

These factors are often treated separately $[1,2]$ and do not take into consideration the fact that, in perceptive experience, the senses reciprocally influence each other (synaesthesia) [3-5].

As our shared experience suggests, and the studies on the healing environment initiated by Ulrich [6] seem to confirm, non-measurable factors (such as the capacity to understand and control the context, the sense of orientation, the capacity to manage situations of environmental stress, etc.) play an equally important part in the determination of environmental comfort as measurable factors. They in fact play a relevant role in the understanding and enhancement of the semantic, psychological, behavioural and social dimensions of dwelling [7-14]. 
At the design stage, non-measurable factors are indicated as objectives to be achieved. These objectives can be verified ex post by way of methodologies (observer-based environmental assessment, evidence-based design approach, customer satisfaction, etc.) aimed at analysing the level of satisfaction of the inhabitants thanks to dialogue and inquiry tools which are typical of sociological analysis [15]. For gathering the opinions of the inhabitants, the challenge to explore and understand non-measurable factors involved in environmental comfort suggests combining quantitative approaches (such as questionnaires) with qualitative approaches such as in-depth interviews, focus groups with experts, observation of physical traces and observation of users' behaviour [16].

The approach that considers human wellbeing as a measurable res extensa is used especially when analysing indoor acoustic comfort, traditionally based on instrumental measurements. Although critical reflections have appeared lately regarding the capacity of decibel-based metrics to determine the acoustic quality of environments and the wellbeing of inhabitants $[17,18]$, deterministic and quantitative approaches are prevalent.

The tendency to see acoustic comfort exclusively in numbers and acoustic design in terms of noise control have as their aim and direct consequence the gradual increase of the acoustic standards of building components. The impact of this approach on the everyday life of people deserves special attention. For example, windows which ensure high levels of sound insulation reduce internal-external interaction, thus obstructing, together with annoying noise, those acoustic elements of a natural type (for example, caused by weather), as well as those of anthropic origin (in other words, deriving from human activities). The resulting reduction of environmental information impoverishes the perceptive experience of the inhabitants, can generate anxiety [19] and decreases, especially among the elderly and people with poor eyesight, the opportunities for controlling the context and for social interaction and participation [20,21]. Considering as "undesirable" all exterior sounds, independently of what they may represent for our lives, reduces our soundmarks and our capacity to discriminate between sounds [16,22].

\subsection{Adaptation and Personalisation of the Living Environment as a Salutogenic Resource}

To place the person-environment relationship at the centre of environmental comfort design highlights the need for an interdisciplinary approach based on contributions from both natural and social sciences. It also raises the issue of managing the complexity of human needs (both measurable and not) in the determination of building standards [23].

The possibility for an inhabitant to adapt the environment in which he lives in order to satisfy his specific needs, to personalise it, to become a shaper rather than a passive subject in its transformation, may be understood as a health factor [24,25], as a coping strategy (that is, an adaptation strategy for identifying and managing stress) $[26,27]$ and, in some contexts (for example, in school buildings), also as an educational resource (see Section 1.4). The inhabitants' capacity to react to the environment-as explained by Antonovsky [28-30] - is intimately related to the level of awareness when acting. It consists in the understanding of what is happening (comprehensibility), in the capacity for interaction (manageability) and in the capacity for judgment (meaningfulness). A conscious inhabitant participates actively in the process of environmental adaptation, knows how to better manage environmental press [31], is more resilient and can better orient himself towards health in the health-disease continuum. To use Antonovsky's own terms, one can say that the environmental adaptation presupposes the "Sense of Coherence" (SOC), i.e., "the ability to comprehend the whole situation and the capacity to use the resources available" [32], and falls within the (external) "General Resistance Resources", i.e., those resources available in the life context to make possible the movement towards health $[28,29,33]$.

The personalisation of the environment is related to the application by the inhabitants of specific solutions aimed at enhancing the interaction with the environment, reducing the environmental press and consolidating spatial appropriation. Personalisation is often analysed in relation to residential environments and with regard to elderly or disabled people [34-37], yet it can be also applied to non-residential environments, within limits that vary depending on the context, with beneficial results 
for the inhabitants. Consider, for example, a room in a nursing home (the possibility to introduce certain furniture or objects belonging to the personal and family history of the inhabitant) or else a school classroom (the possibility to periodically modify the layout of the classroom, also in view of achieving specific educational objectives).

Among the forms of environmental adaptation, the possibility that the inhabitants have to intervene autonomously in environmental parameters (temperature, sound level, natural and artificial lighting, ventilation, etc.) and to personalise their dwelling space in order to feel it as part of their lives and more fitting to their needs is pivotal. Environmental factors that are constant through time, although considered optimal, can bring about a condition of physical discomfort termed "environmental boredom" [38]. For example, some research [7,39] has shown that naturally ventilated interior spaces are far more stimulating and pleasant than those that have a static interior climate obtained through centralised air-conditioning. This leads to a reflection on the meaning of comfort itself and on the distinction between the static and adaptive approach to environmental comfort $[16,40]$.

The importance of the control and dynamic adaptation of the environmental parameters by the inhabitants can be better understood when considering that individual factors such as age, sex, health conditions, functional limitations, lifestyle, social context, etc., affect all human needs, including those of a "physiological" nature [21,41,42]. Since the response to environmental stimuli is subjective, nothing guarantees that the respect of performance standards contemplated by rules and regulations can ensure the wellbeing of every person $[23,37]$.

\subsection{Specificity of Acoustic Comfort}

Although the conditions of thermal comfort depend mainly on physiological factors-due to differences in metabolism, these conditions change in women and men [43-46], in children and elderly persons [46-48], as well as in pregnant women [49]—in the case of acoustic comfort, other factors of a different nature are involved.

It is well known, for example, that in addition to the "normal" weakening of hearing as a result of ageing (presbyacusis; from the age of 12 , and in particular concerning sounds at a frequency of approximately $4000 \mathrm{~Hz}$ ), acoustic comfort is greatly influenced by environmental, cultural and behavioural factors (soundscape) [50-52]. The latter are, in turn, often related to the type of sound and the age of the person who listens. For example, Yang and Kang [53] have observed that "with an increase in age, people are more favourable to, or tolerant towards, sounds relating to nature, culture or human activities".

In assessing acoustic quality, even the context and activities carried out in it play an important role. Consider, for example, the differences in terms of aural message and communicative and symbolic charge between the nave of a church and a classroom. Although the high reverberation time of churches (especially older ones, where solemn liturgies are held) hinders speech understanding, it emphasises the mystical and sacred dimension of the place of worship [54,55]. In a classroom, on the other hand, speech understanding must be favoured since it is essential to the teaching and learning activities.

It is necessary to highlight as well the specific traits of acoustic comfort when compared to thermal, lighting or ventilation comfort, also regarding the possibility that the user has of controlling the environmental factors. Temperature, lighting and ventilation can be regulated by intervening directly on the building components (windows, shading systems, etc.) or on technological devices (thermostats, lighting dimmers or advanced sensor systems such as wearable sensors [56], etc.). Regarding sound, however, except in those cases when the undesired sound comes from a sound system, this is not possible. In order to enhance the acoustic quality of a place, it is necessary to intervene in the passive features of the environment (sound reduction index of the enclosure, sound absorbing coefficient of materials, distribution of sound absorbing surfaces, etc.). The impossibility to control/regulate the acoustic conditions of an environment can generate a strong sense of frustration in the inhabitants and contributes to making acoustic discomfort one of the main causes of stress in city life [57]. 


\subsection{The Acoustic Quality of Learning Spaces}

Learning spaces represent an interesting field for applying the considerations expounded above. As indicated in the Ottawa Chart, these are privileged places for the promotion of health [24]. According to Wright [58], "At its worst, the built environment can undermine the learning process, inhibit pupil attainment and damage pupil and staff well-being. At its best, good design has the capacity to enhance the educational experience and transform the school as a learning organisation and workplace".

Ideas on acoustic comfort thus become pivotal in the design/regeneration of school classrooms.

Some studies have demonstrated the correlation between the acoustic quality of school classrooms and the level of performance of students $[59,60]$. A good acoustic quality of learning spaces, in fact, favours appropriate cognitive and metacognitive functioning and processing of the gathered information. In this manner, it ensures the conditions for a comfortable, constructive and stimulating learning environment and has a direct influence on the performance of the students [59].

According to Connolly [61], adolescents are very sensitive to their school's acoustic environment and to the disruption to teaching and learning caused by poor listening conditions. Furthermore, pupils with congenital or trauma-acquired hearing impairments [62] or with additional learning needs are more at risk from the negative effects of poor acoustics.

Although taking into account the specific differences in the perception of sound between children and adults [63], the effects of poor acoustic quality in a classroom also concern the teachers. According to Astolfi [64], in classrooms with a high reverberation time, teachers are induced to raise their voice in order to be understood by students $[65,66]$. High noise levels can cause dysphonia or other vocal pathologies in teachers [67-69], which in turn can determine increased listening difficulties in children [70].

In addition, a correlation between acoustic quality and the teaching performance of the teacher was observed [71-73].

\section{Research Aims}

This paper concerns the classrooms of primary schools and is inspired by a salutogenic vision of acoustic comfort. It is based on a research project from the University of Florence [74,75] carried out by a work group which included, in addition to the authors of this paper (researchers in the field of architecture), researchers in the field of education science. This research enquired into the reduction of reverberation times in school classrooms and the relationship between reverberation and speech understanding by the students.

The paper is organised into three closely interrelated phases.

The first phase concerns the gathering of knowledge regarding the phenomenon in question and is based on "traditional" measuring methods for determining the typical acoustic response of classrooms belonging to various typologies of primary school buildings.

The second phase is aimed at determining the percentage of surface covered by sound-absorbing material necessary for reducing the reverberation times in relation to the volume of a typical classroom.

The third phase is aimed at the design of solutions for improving the acoustic performance of the typical classroom. This phase is based both on the involvement of the students and on their participation in the process of personalisation and adaptation of the learning space [24,76,77].

The aim of this work consists in determining a system for the acoustic correction of classrooms, which may:

1. Combine acoustic performance with pedagogical-educational value and the aesthetic quality of spaces [78-82];

2. Stimulate the children's imagination, curiosity and creativity, thus contributing to teaching them about the acoustic dimension of dwelling $[80,83]$. 
In the case of primary schools, the "intangible" aspects, as well as those connected to the possibility of personalising and transforming space, take on a great importance, especially regarding children aged 6 to 11, who are particularly sensitive to environmental and spatial defects [58,81,84].

The acoustic correction system proposed is designed to be partially self-built by the students under their teachers' supervision.

Some research and experimentation carried out in the field of the social sciences have shown that the direct involvement of students in the process of formal determination and configuration of the learning space is a teaching tool that can stimulate both a sense of belonging and identification with the school, as well as various aspects of their personality [58,71]. In these studies, an increase in self-esteem and personal motivation have been observed in students, with positive effects on their academic performance $[81,85]$ and on their health.

In our study, the participation of the students in the acoustic correction was limited, however, to those parts of the work that could be carried out with adequate safety conditions and the parts which required professional equipment and skills were entrusted to specialised personnel.

The verification of the student's satisfaction, which is one of the research aims, will be carried out in the future developments of the study.

\section{Materials and Methods}

\subsection{Analysis of the Acoustic Performance of a Representative Sample of Primary School Classrooms}

In the context of the research which underlies this paper, numerous measurements were taken with the purpose of determining the "typical" acoustic response of classrooms belonging to different types of school buildings [86,87] in a specific area (Municipality of Florence).

The Municipality of Florence has a total of 55 primary schools, the largest portion of which $(29 \%)$ was built between 1961 and 1975, as can be seen in Figure 1.

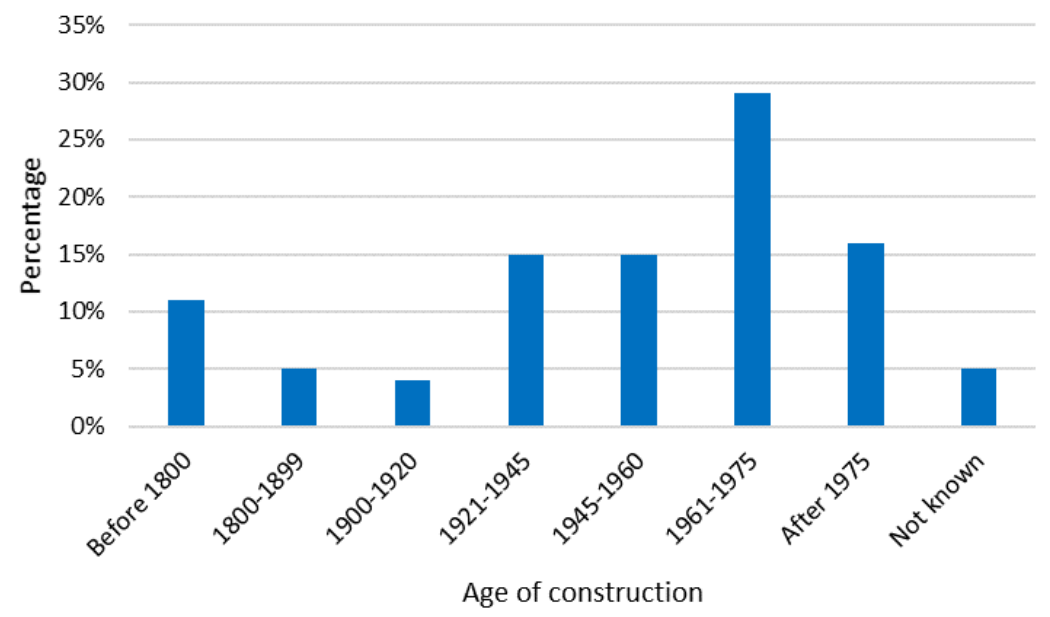

Figure 1. Percentage distribution by age of construction of the schools of the Municipality of Florence.

Measurements of 52 classrooms from 19 primary schools were carried out between 2018 and 2020. These schools are representative, regarding the time of construction, of the complete sample illustrated in Figure 1.

These measurements consider several parameters of room acoustics (reverberation time, RT, clarity, $\mathrm{C}_{50}$, speech transmission index STI), yet, for the purposes of this study, only the results concerning reverberation time were considered, since this parameter is commonly used at the design stage. All measurements were carried out in unoccupied classrooms where only two technicians and the normal furniture of the room were present, as indicated by the Italian standard UNI 11367 [88]. 
In order to determine the specific techniques for the drafting of the acoustic improvement project, reference was made to optimal RT values as determined by Italian regulations [88].

Indeed, Annex C of UNI 11367 [88] gives the optimal RT values, $\mathrm{RT}_{\mathrm{opt}}$, in indoor spaces used for speech (schools and others), in which $\mathrm{V}$ is the volume of the space $\left(\mathrm{m}^{3}\right)$ :

$$
R T_{\text {opt }}=0.32 \lg (V)+0.03(s)
$$

If referring to the typical volume of $150 \mathrm{~m}^{3}$ of a classroom, $\mathrm{RT}_{\text {opt }}$ is $0.7 \mathrm{~s}$.

This optimal value refers to unoccupied indoor spaces and is limited to the octave frequency bands of 500 and $1000 \mathrm{~Hz}$. Indeed, these are the typical frequency bands of speech.

This optimal value is similar to the ones determined in many European countries. According to Rasmussen [89], to optimise speech intelligibility for listeners and minimise the voice load of teachers, in Nordic European countries, there is an optimal value of RT of approximately $0.6 \mathrm{~s}$.

Furthermore, according to UNI 11367 [88], in indoor unoccupied spaces, the RT must fulfil the following limit between the octave bands of 250 and $4000 \mathrm{~Hz}$ :

$$
\mathrm{RT} \leq 1.2 \mathrm{RT}_{\mathrm{opt}}(\mathrm{s})(250 \div 4000 \mathrm{~Hz})
$$

With reference to the volume and to the measured and the optimal value $(500-1000 \mathrm{~Hz})$ of RT, it is possible to define, for each classroom, the equivalent absorption area, $\mathrm{A}_{\text {req, }}$, that is necessary in order to fulfil the optimal value of reverberation.

The equivalent absorption area, $\mathrm{A}$, is the surface of the totally absorbing material ideally present in a room to provide the desired RT and is given by the product of the surface of a material and its absorption coefficient.

Indeed, from the well-known Sabine relation between RT and the equivalent absorption area existing in the classroom, $\mathrm{A}_{\text {exist }}$ [90], it is possible to calculate the additional absorption area that must be added in each classroom, $\mathrm{A}_{\mathrm{add}}$, to obtain $\mathrm{RT}_{\mathrm{opt}}$, according to Equations (3) and (4).

$$
\begin{aligned}
A_{\text {add }}=A_{\text {req }}-A_{\text {exist }} & =0.16 V\left(\frac{1}{R T_{\text {opt }}}-\frac{1}{R T_{\text {exist }}}\right) \\
S_{\text {add }} & =\frac{A_{\text {add }}}{\alpha_{\text {add }}}
\end{aligned}
$$

where

$\mathrm{A}_{\mathrm{add}}=$ addition sound absorption area required to obtain $\mathrm{RT}_{\mathrm{opt}}$ in the classroom $\left(\mathrm{m}^{2}\right)$;

$\mathrm{A}_{\text {req }}=$ sound absorption area referred to $\mathrm{RT}_{\mathrm{opt}}\left(\mathrm{m}^{2}\right)$;

$\mathrm{A}_{\text {exist }}=$ sound absorption area existing in the classroom $\left(\mathrm{m}^{2}\right)$;

$\mathrm{V}=$ volume of the classrooms $\left(\mathrm{m}^{3}\right)$;

$\mathrm{RT}_{\mathrm{opt}}=$ optimal value of RT referred to the volume of the classroom (s) given by Equation (1);

$\mathrm{RT}_{\text {exist }}=$ existing measured $\mathrm{RT}$ in the classroom (s);

$\mathrm{S}_{\mathrm{add}}=$ additional surface of the absorbing material $\left(\mathrm{m}^{2}\right)$;

$\alpha_{\text {add }}=$ absorbing coefficient of the additional absorbing material (-).

\subsection{Analysis of the Typical Solutions for the Acoustic Correction of School Classrooms}

\subsubsection{Description of the Most Widespread Sound-Absorbing Solutions Used in Italy}

In order to determine the amount of sound-absorbing surface for each classroom $\left(\mathrm{S}_{\mathrm{add}}\right)$, it is necessary to refer to the acoustic performance of the elements typically used for the acoustic correction of school classrooms. In this respect, the most widespread solutions available in the Italian market were analysed by consulting the websites of the main Italian and international companies that operate in the acoustic field [74,91]. 
The analysis was carried out with the purpose of drafting a proposal that is consistent with the current production, trying to use standard and modular products, which are easily available in the market, economical and easily applicable to the existing school classrooms.

Three main types of sound-absorbing elements emerged from the study:

(a) Wall panels;

(b) Hanging panels;

(c) Panels or 3-D elements placed on the ground.

For all three categories, which will be briefly described below, the most widespread material is polyester fibre, since, in addition to its good sound-absorbing qualities, it is fireproof, non-allergenic, very light and economical [92]. Moreover, the polyester fibre combines excellent tear resistance at a very low cost (which would facilitate the replacement of any damaged elements); this can limit the effects of possible vandalism by the students. Furthermore, it can be considered to be a sustainable material since it can be obtained up to $100 \%$ from recycled material (PET) and can be recycled at the end of its life cycle [93,94].

\section{(a) Wall panels}

Among the solutions present in the international market, the use of wall panels is the most common. These panels are usually placed on the walls until they have covered the necessary surface for obtaining the desired acoustic correction.

From an aesthetic point of view, wall panels come in different shapes, sizes, colours and finishing, which, when installed, offer a vast array of geometrical shapes and textures, capable of aesthetically qualifying the space in question.

Two main usages can be identified. The first consists in the use of panels with simple geometrical shapes (rectangular or square), combined with different colours so as to compose mosaics which reproduce patterns and motifs at the choice of the designer. The second consists in the use of panels with more complex geometrical shapes (pentagons, hexagons, petals, etc.) which, placed side by side, create patterns through the repetition of a basic module. Moreover, in this second solution, it is possible to use panels with different colours and textures, so as to embellish motifs and patterns.

Wall panels represent a typical solution for acoustic correction, which is also easy to install. They are fastened to the wall by gluing or by mechanical fixing (e.g., by anchoring to a substructure through wall plugs; Figure 2).

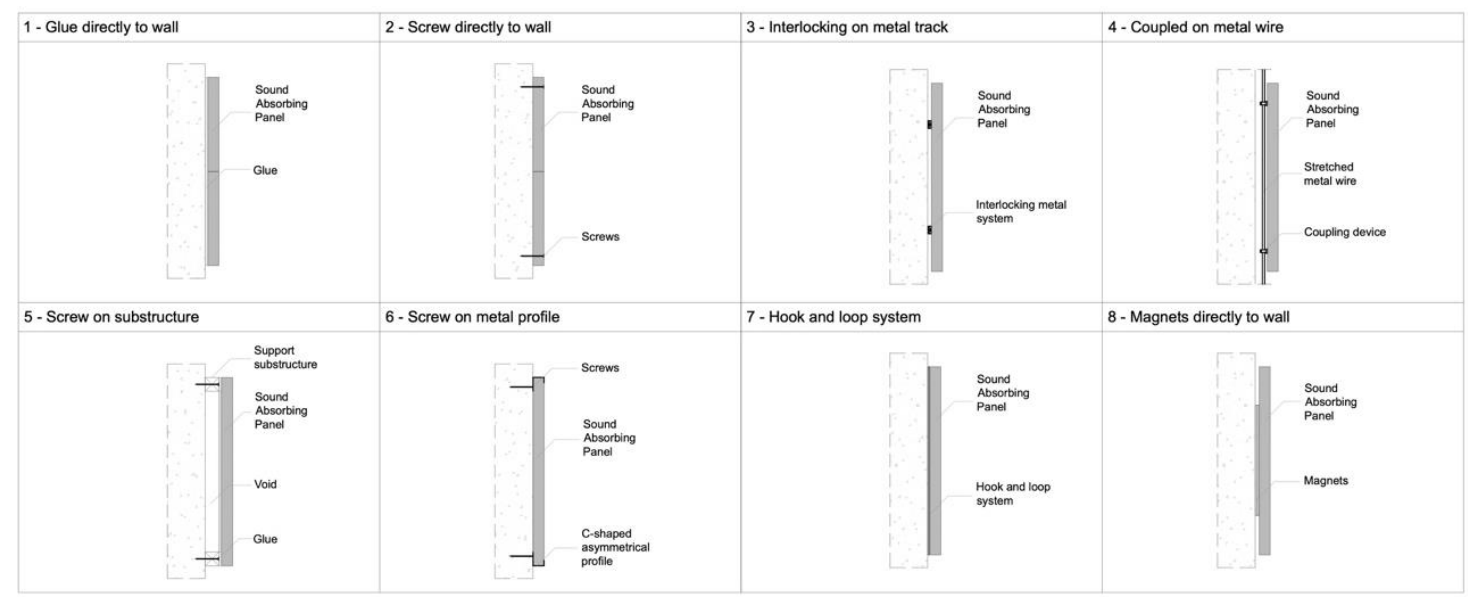

Figure 2. Possible methods for fastening two-dimensional sound-absorbing elements to walls.

Unlike the other solutions, however, wall panels can cause interference with the openings (doors and windows) of the classroom, with the exposed educational material or with any possible exposed 
device on the walls (electricity, fire-extinguishing system and other technical elements present on the walls).

(b) Hanging panels

The use of hanging panels can be a good option in school classrooms that have the necessary height, whenever it is desired to leave the walls free.

Sound-absorbing elements can be hung directly from the ceiling (or false ceiling) or else hooked onto steel cables extended between opposing walls; see Figure 3. This second solution may be preferable for safety reasons (in order to avoid the fall of sound-absorbing elements or the detachment of sections of the ceiling or false ceiling). In this case, the sound-absorbing panels can be hung as "islands" (parallel to the ceiling) or as "baffles" (perpendicular to the ceiling).

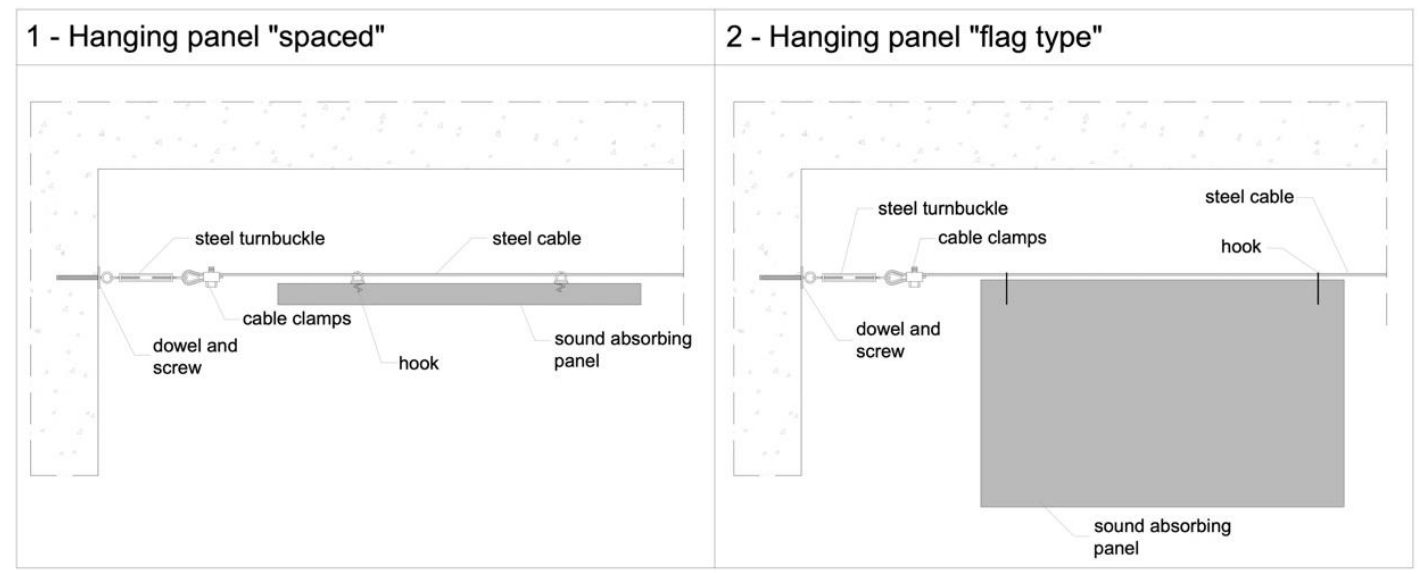

Figure 3. Possible hanging system for sound-absorbing elements using steel cables and hooks placed either as islands (left) or baffles (right).

(c) 3D elements or panels placed on the ground

The use of elements resting on the ground is the least common acoustic correction solution, yet it is perhaps one of the most interesting from the point of view of the qualification and configuration of space. The elements placed on the ground can be two-dimensional (panels) or three-dimensional (volumes). They come in various forms and sizes and can become seats, stands or even proper furniture (acoustic furniture).

These elements, unlike those previously described, generate an interaction with the people present in the space and can be used and moved according to need. The possibility of becoming furnishing elements constitutes a feature that ascribes great expressive and compositional potential to these design solutions.

However, the lack of space and the mobility requirements within the average school classroom makes their application difficult in most cases.

\subsubsection{The Chosen Sound-Absorbing Solution}

Once the survey described above was concluded, for the test, it was decided to use solution a) and, specifically, 5-cm-thick polystyrene fibre wall panels. Figure 4 shows the acoustic absorption coefficient of this kind of panel, which was used to correct some classrooms involved in the research.

\subsection{Definition of the Typical Classroom}

In order to develop a system for the acoustic correction of classrooms that can be applicable to as many cases as possible, it was necessary to first determine the features of a typical classroom. 


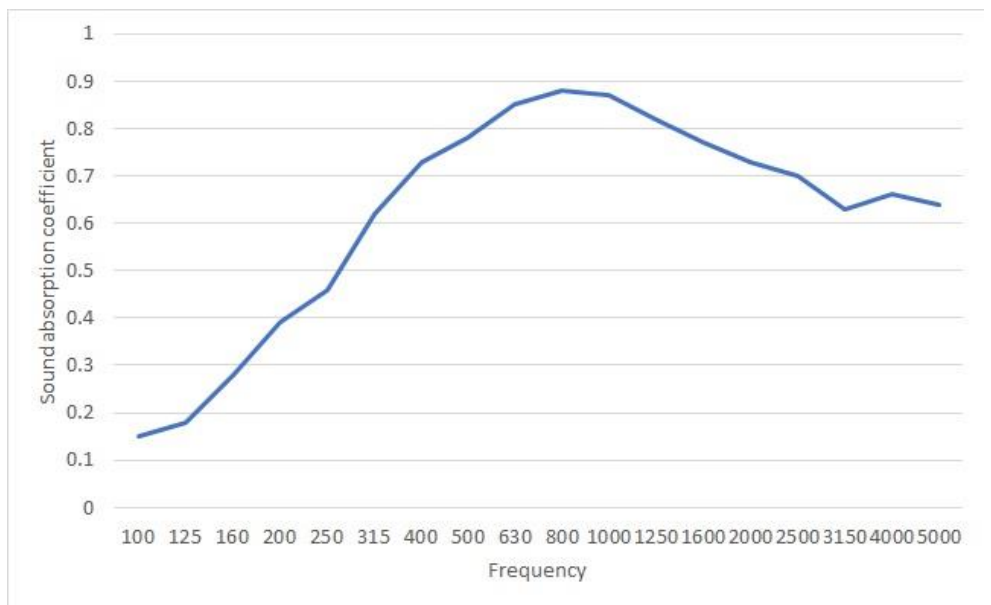

Figure 4. Sound absorption coefficient of a 5-cm-thick polystyrene fibre panel.

The definition of the typical school classroom was undertaken based both on the average dimensions of the classrooms examined (characterized by an average volume of about $150 \mathrm{~m}^{3}$ ) and on the spatial and environmental requirements determined by the Italian regulations in force-that is, D.M. 18/12/1975 and its subsequent amendments and additions [95]. In accordance with this decree, the classrooms of primary schools should have a surface between 45 and $50 \mathrm{~m}^{2}$ and a minimum net height of $3 \mathrm{~m}$. In order to ensure an average daylight factor of 3\%, the surface covered by windows usually varies between $1 / 5$ and $1 / 6$ of the floor surface (from 7.5 to $10 \mathrm{~m}^{2}$ ). The school classroom usually accommodates between 25 and 30 pupils, in addition to the teacher/s. The classroom always includes: (1) teaching devices (whiteboard, interactive whiteboard, etc.), (2) furniture for placing objects (wardrobes, shelves, hall stands, etc.) and often (3) educational material (posters, pictures, maps, etc.) made by the students.

Subsequently, through the morphological-dimensional analysis of the sample consisting of the 52 analysed classrooms (see Section 3.1), the typical classroom from Figure 5, which presents a surface of $45 \mathrm{~m}^{2}$, an average height of $3.2 \mathrm{~m}$ and a volume of approximately $145 \mathrm{~m}^{3}$, was designed.

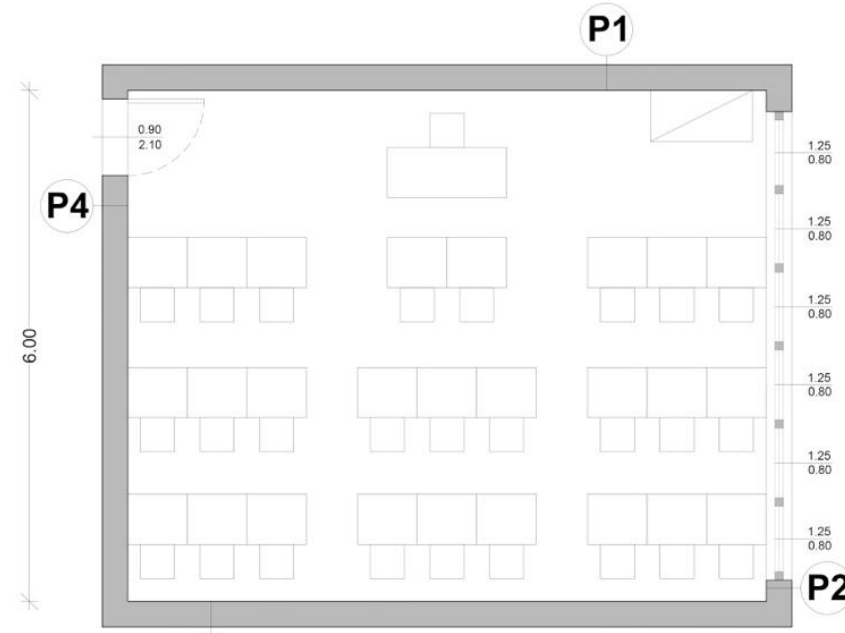

P3

Figure 5. Planimetric layout of the typical classroom. 
This typical classroom is not fully representative of the entire sample of examined classrooms but is exemplary of those classrooms that fulfil the current technical standards for Italian schools.

The minimum surface of the sound-absorbing elements, as well as their placement and the system for fixing them, were determined on the basis of this typical classroom.

\section{Results}

\subsection{Results of Measurements in the Case Study}

Figure 6 shows the average RT in the sample of 52 classrooms with error bars $(+/-$ standard deviation), with the optimal values (dotted line) given by UNI 11367 [88], referring to the average volume of the sample of classrooms examined [96].

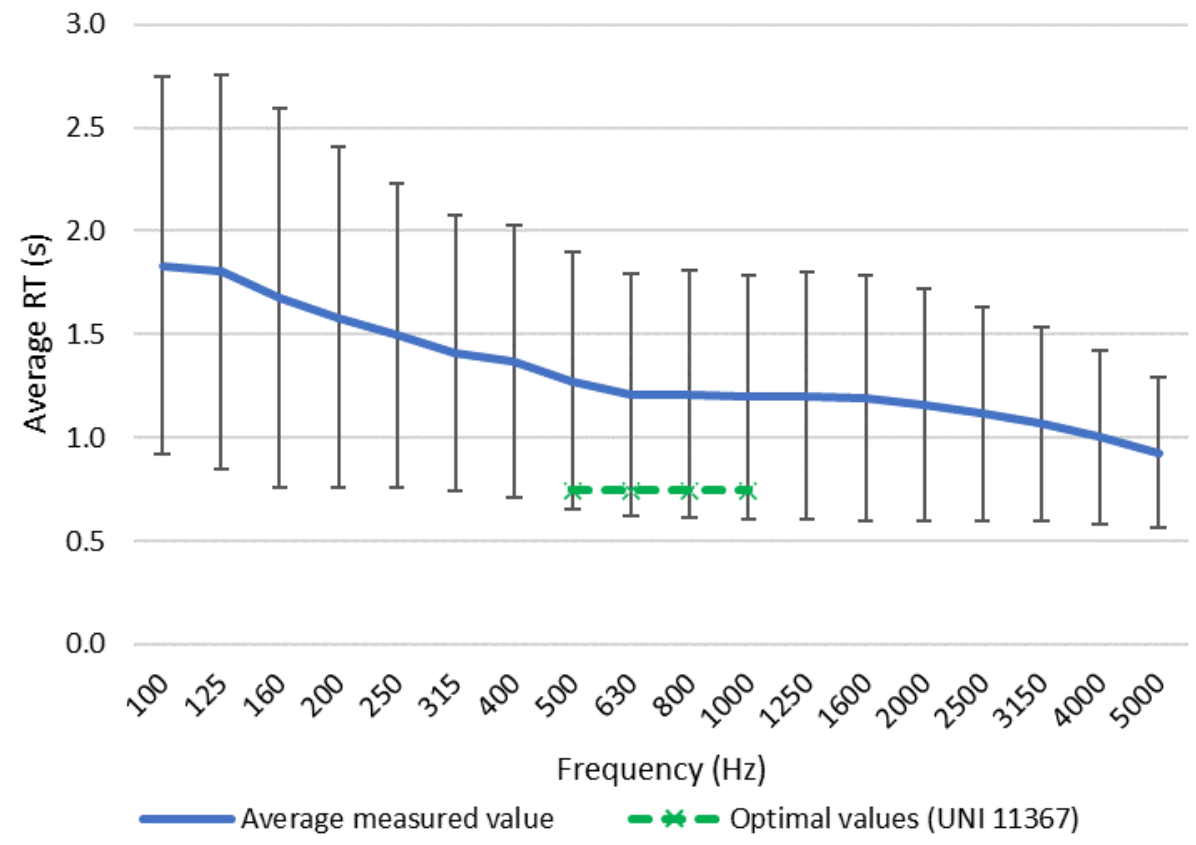

Figure 6. Average value with error bars ( \pm st. dev.) of the measured RT of 52 classrooms in Florence compared to the limit value given by UNI 11367 [88] for their average volume.

It is evident that in almost all the examined classrooms, RT greatly exceeds the optimal value established by UNI 11367 [88] and should therefore be corrected with sound-absorbing material, according to Equations (3) and (4).

Figure 7 shows the percentage distribution of the sample of 52 classrooms with the ratio between the average measured value $(250 \div 4000 \mathrm{~Hz})$ and the limit value of RT (Equation (2)). Only $34 \%$ of this case study of classrooms fulfills the limit determined by UNI 11367 [88].

Figure 8 highlights, exclusively in the case of the examined classrooms which have no previous sound-absorbing treatment, the ratio between the sound-absorbing units $\mathrm{A}\left(\mathrm{m}^{2}\right)$ necessary in every classroom so as to obtain the optimal value of RT between 500 and $1000 \mathrm{~Hz}$ [88] and the respective volume $\mathrm{V}\left(\mathrm{m}^{3}\right)$ of each classroom. 


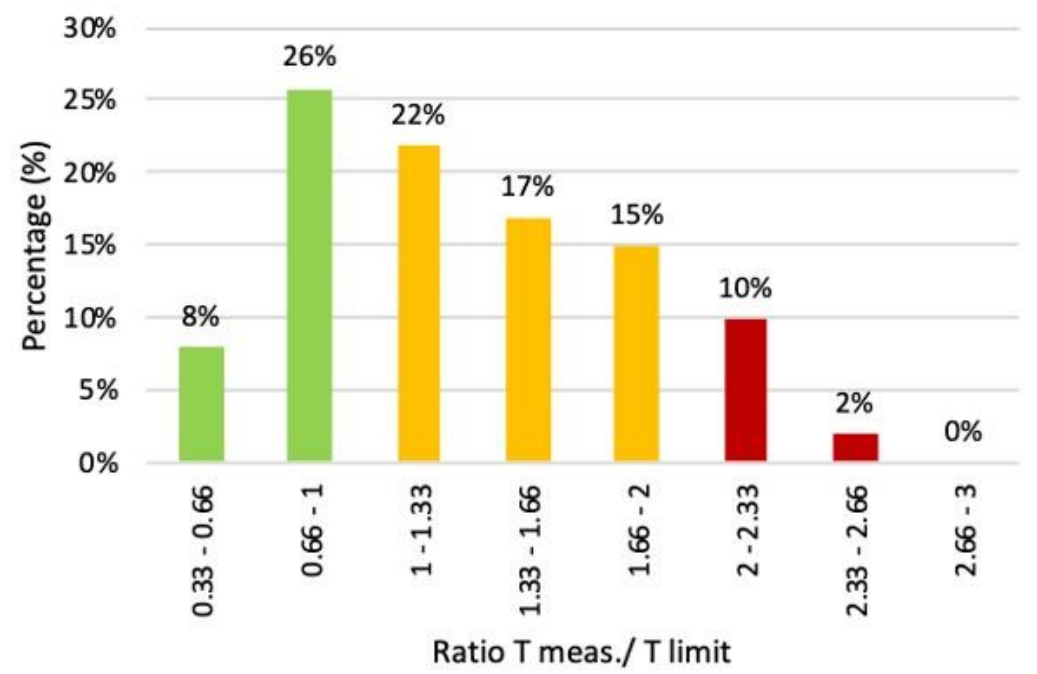

Figure 7. Percentage distribution of classrooms with respect to the ratio between the measured value of RT and the limit value given by UNI 11367 [88], referring to the volume of each classroom.

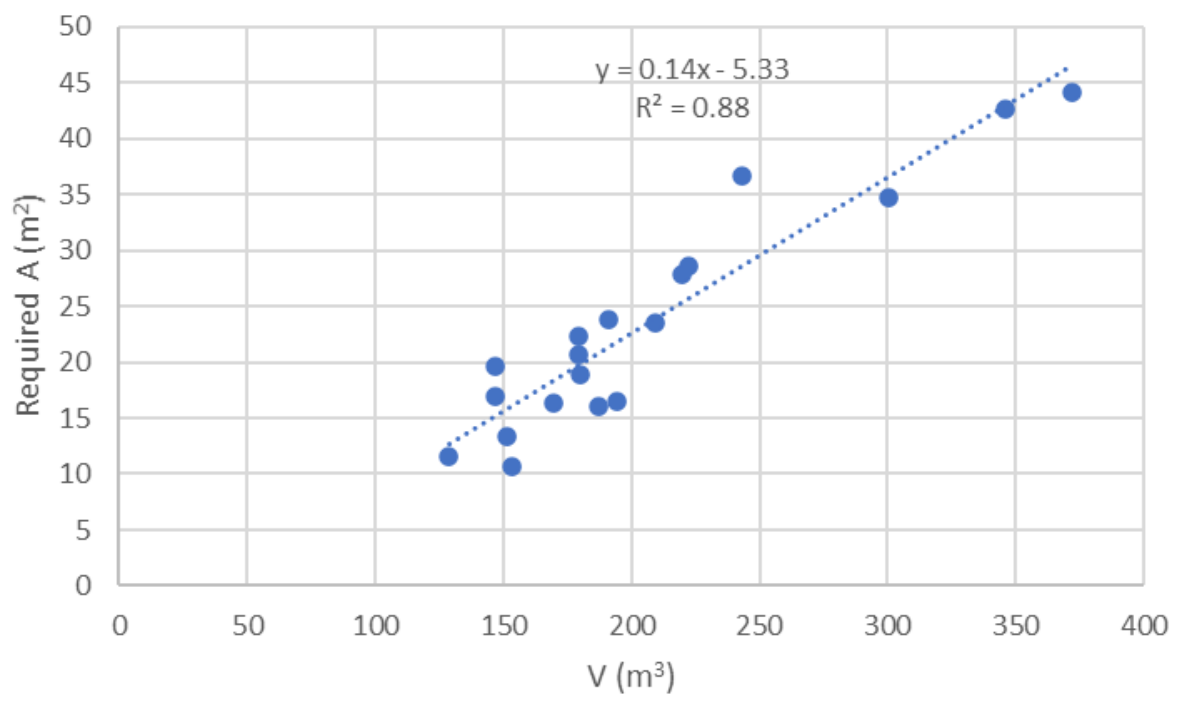

Figure 8. Correlation between the required equivalent absorption area (A) and the volume (V) of each classroom.

The correlation between the volume of the classroom (V) and the total additional equivalent sound-absorbing surface $\left(\mathrm{A}_{\mathrm{add}}\right)$ necessary for optimising $\mathrm{RT}$ in each classroom can be deduced from Figure 8 and from Equation (5).

$$
A_{\text {add }}=0.14 V-5.33\left(\mathrm{~m}^{2}\right),
$$

Considering the volume of the examined classrooms, which varies between 130 and $370 \mathrm{~m}^{3}$, the amount of sound-absorbing units that need to be placed in these classrooms is variable, based upon Equation (5), between 10 and $45 \mathrm{~m}^{2}$, the larger number corresponding to larger classrooms.

Nevertheless, it must be noted that around $80 \%$ of these classrooms have a volume between 130 and $220 \mathrm{~m}^{3}$, since only three classrooms have a volume greater or equal to $300 \mathrm{~m}^{3}$ because of their very great height.

When referring to the typical classroom described in paragraph $3.3\left(\mathrm{~V}=145 \mathrm{~m}^{3}\right)$, Equation (5) gives a result of approximately $15 \mathrm{~m}^{2}$.

It is however possible to generalise the problem and refer to the average RT values measured in the various examined classrooms. 
Figure 9 shows the difference between the average of the existing sound-absorbing units in the examined classrooms and those required in accordance with UNI 11367 [88] (optimal values and minimum values according to Equations (1) and (2)) at frequencies between 250 and $4000 \mathrm{~Hz}$.

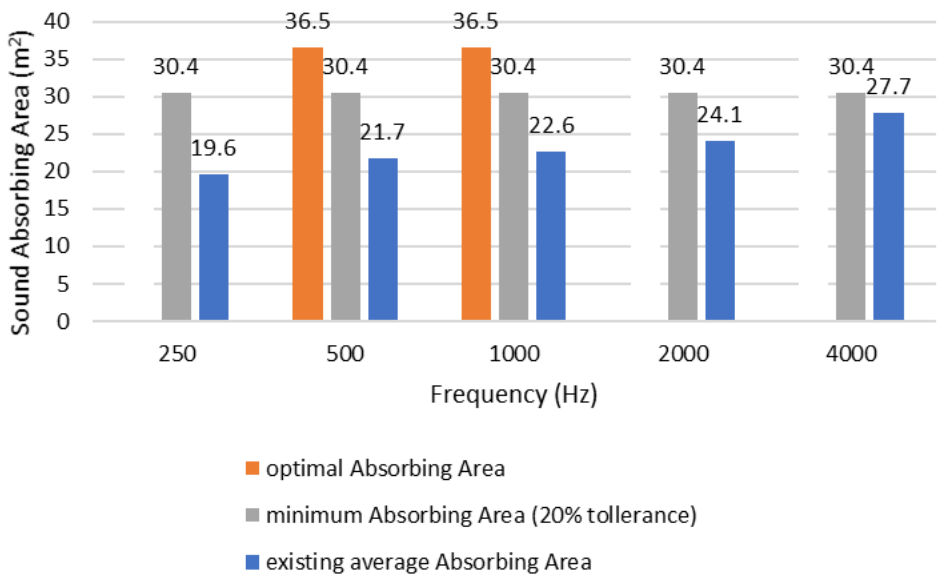

Figure 9. Difference between average values of existing absorption areas and absorption area required to achieve optimal (500-1000 Hz) and minimum (250-4000 Hz) values of RT according to UNI 11367 [88].

From the results shown in Figure 9, it emerges that the average number of sound-absorbing units necessary for correcting the classrooms varies between 14 and $15 \mathrm{~m}^{2}$ in the range from 500 to $1000 \mathrm{~Hz}$. This quantity is sufficient also considering the octave band of $250 \mathrm{~Hz}$, as a consequence of the $20 \%$ tolerance given by the Italian standard [88].

In the case of cladding with 5-cm-thick polystyrene panels, considering the number of sound-absorbing units necessary for the typical classroom $\left(15 \mathrm{~m}^{2}\right)$ and the value of the sound absorption coefficient at the frequency of $500 \mathrm{~Hz}(\alpha=0.78$, Figure 4), the sound-absorbing surface $\left(S_{\text {add }}\right)$ that needs to be introduced in the typical classroom can be deduced from Equation (6).

$$
S_{a d d}=\frac{A_{\text {add }}}{\alpha_{\text {add }}}=\frac{15}{0.78}=19.2\left(\mathrm{~m}^{2}\right),
$$

This result, approximately $20 \mathrm{~m}^{2}$, refers, according to the expounded methodology, to a sample of furnished classrooms which have no relevant presence of sound-absorbing elements.

This result is based on an analysis that considered only middle-frequency sounds (500-1000 Hz), which are the most important for understanding speech.

Considering the octave band of $250 \mathrm{~Hz}$, the minimum additional equivalent sound-absorbing surface would be around $11 \mathrm{~m}^{2}$ (Figure 9) and the consequent surface of polystyrene panel would be around $24 \mathrm{~m}^{2}(\alpha=0.46$ at $250 \mathrm{~Hz}$, Figure 4$)$.

Nevertheless, in order to correct RT at lower frequencies, it would be preferable to use solutions other than polystyrene fibre panels, such as resonant perforated panels.

\subsection{The System for the Acoustic Correction of School Classrooms}

The proposed sound-absorbing system attempts to combine acoustic performance, aesthetic quality and learning requirements. At the core of the system lies a series of requirements, the most important of which are illustrated in Table 1. 
Table 1. Main requirements of the system for the acoustic correction of school classrooms.

\begin{tabular}{|c|c|}
\hline \multicolumn{2}{|c|}{ Requirements } \\
\hline Quantitative & Qualitative \\
\hline Reduction of RT & Speech understanding and access to information \\
\hline $\begin{array}{l}\text { Control of the superficial roughness of } \\
\text { phono-absorbing panels }\end{array}$ & Bettering of learning performance \\
\hline Absence of bad smells & Educational value of the experience \\
\hline Stability & $\begin{array}{l}\text { Strengthening of the identity } \\
\text { of the classroom group }\end{array}$ \\
\hline Fire safety & Reduction of voice disorders in teachers \\
\hline User safety & $\begin{array}{l}\text { Personalisation and control of the } \\
\text { environment by the students }\end{array}$ \\
\hline Reversibility & Self-buildability of the system \\
\hline Durability & Aesthetic quality \\
\hline Easy to maintain and clean & - \\
\hline Easy to produce, transport and assemble & - \\
\hline Dimensional modularity and adaptability & - \\
\hline $\begin{array}{l}\text { Disassembly, dismantling and recycling of the products (panels } \\
\text { and supporting elements) at the end of their life cycle }\end{array}$ & - \\
\hline Low cost & - \\
\hline
\end{tabular}

The system is based on the use of 5-cm-thick rectangular, square and triangular polystyrene fibre sound-absorbing panels. The sizes and shapes proposed for the individual panels, do not, however, bind the inner logic of the system. Indeed, this system may consist of sound-absorbing panels of varying shapes and sizes, provided the necessary amounts are used for achieving the necessary reduction in reverberation times.

From the result of Equation (6), the sound-absorbing surface to be introduced into a typical classroom with a $145 \mathrm{~m}^{3}$ volume is approximately $20 \mathrm{~m}^{2}$.

The system consists of two distinct parts:

- The first part, with a fixed configuration, consists of absorbing panels of equal size placed along the line of contact of the wall with the ceiling or false ceiling. Its installation (also due to the height) requires the presence of specialised personnel and the use of professional equipment. This part of the system is referred to as the "cornice".

- The second part, which has a variable configuration, consists of removable panels placed on the wall starting from a height of $70 \mathrm{~cm}$ above ground level. Excluding the support structure, this section can be self-constructed by students under the guidance of teachers and does not require the use of professional equipment. This part of the system is referred to as the "acoustic shapes" and will be provided in the form of an assembly kit, which will be described below.

Based upon the geometry of the typical classroom in Figure 5, the sections of the walls on which to place the sound-absorbing panels (both the "cornice" and the "acoustic shapes" types) were determined, limiting as much as possible the interference with the existing elements (openings, building systems networks, furniture and educational material). In fact, as exemplified in Figure 10, the walls are not all equally available for accommodating the sound-absorbing panels, since each has specific constraints. P1 wall, located behind the teacher's desk, is usually occupied by the blackboard. This wall, together with the two side walls (P2 and P4), is also frequently used to hang posters or pictures made by the students. Furthermore, P2 and P4 walls usually include the windows or entrance door, respectively. The remaining wall (P3), located at the back of the classroom, is generally free and is therefore the most adequate for accommodating the largest quantity of sound-absorbing elements. 


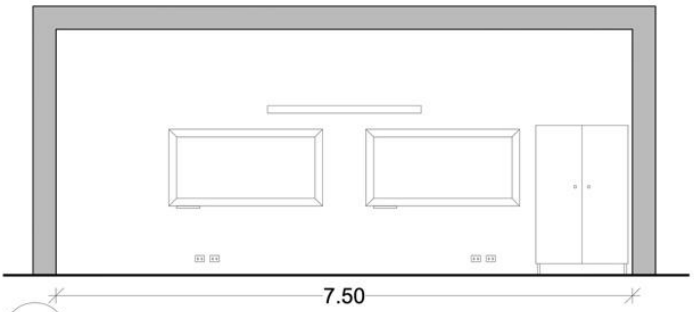

P1

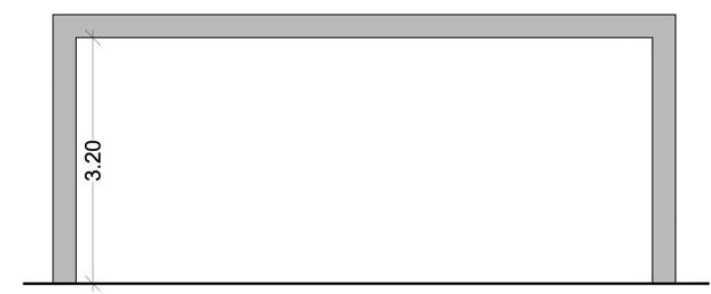

P3

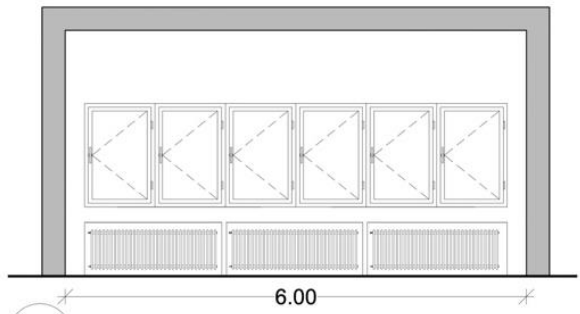

P2

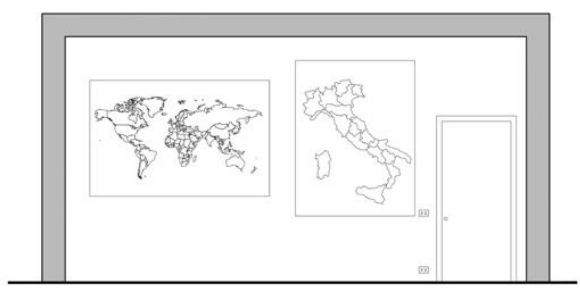

P4

Figure 10. Layout of the typical classroom walls, with indications of the main building components and school furniture.

Considering the available space on the walls of the typical classroom and the sound-absorbing surface determined in Section $4.1\left(20 \mathrm{~m}^{2}\right)$, the ideal shapes and locations for the acoustic panels (both those belonging to the part called "cornice" and those belonging to the part called "acoustic shapes") were identified; see Figure 11.

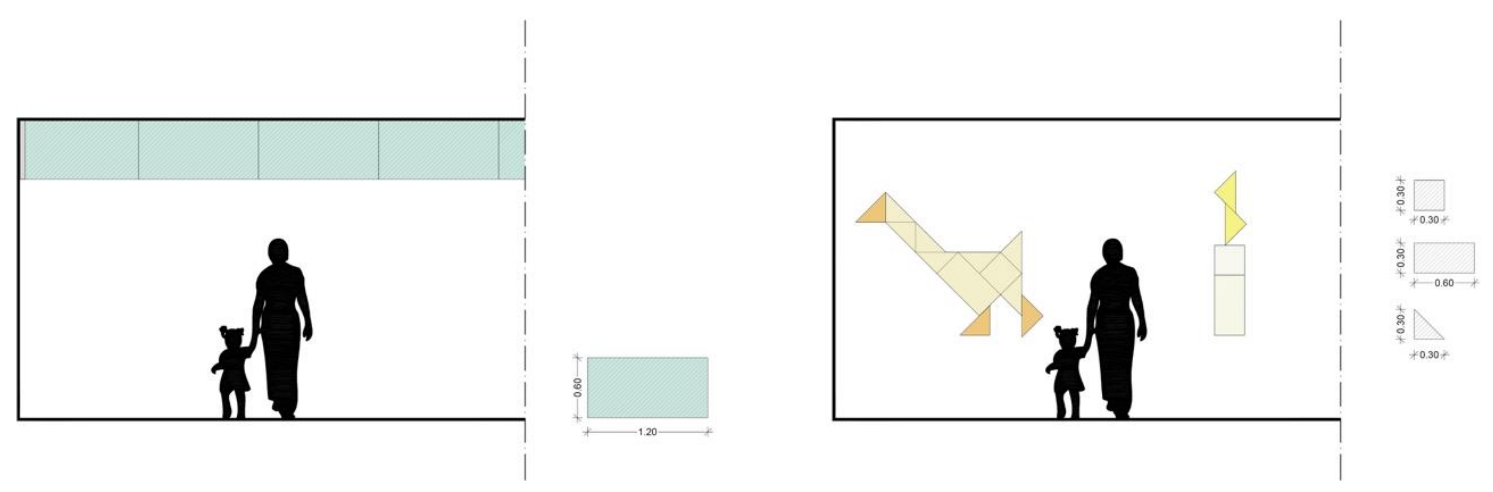

Figure 11. To the left, the fixed part of the system for acoustic correction made of standard panels ("cornice"); to the right, an example of the variable configuration part of the system ("acoustic shapes").

As for the fixed "cornice" panels, considering that the perimeter of the average classroom is equal to $27 \mathrm{~m}$ and the presence of windows on one of the lateral walls (P2 in the example in Figure 10), the overall surface covered by sound-absorbing panels should be equal to $16 \mathrm{~m}^{2}$ (prudentially considering only the surface of the panels and not their thickness which, however, has an effect on the degree of sound absorption).

Some sources [97] suggest not placing sound-absorbing elements on the wall behind the teacher (P1) so as to favour the diffusion of soundwaves in the direction of the students. It is our belief, however, that the use of a section of the wall behind the teacher for placing some sound-absorbing panels does not have a significant impact on the vocal effort of the teacher. It is also important to bear in mind that in primary schools, frontal teaching is only one of several pedagogical methods used and that the relationship between students and teachers, or among students, more and more takes on 
dynamic and greatly interactive forms [98]. Consequently, more flexible school furniture arrangements as well as more interactive, participatory and collaborative learning spaces have been considered [99].

The "cornice" part was chosen for reasons of safety (to avoid fastening hanging panels to the ceiling or false ceiling), as well as because the upper section of the wall is usually free from the presence of openings, technical elements (tubing, emergency lights, junction boxes, piping, etc.) and furniture; see Figure 12. Therefore, this solution ensures the necessary versatility of the system and the possibility of adapting it to the various school classroom typologies.

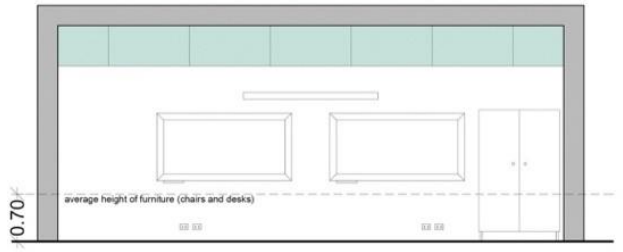

P1

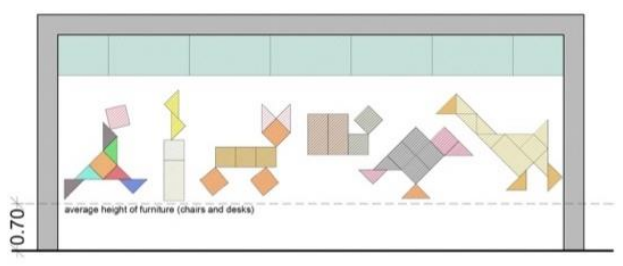

P3

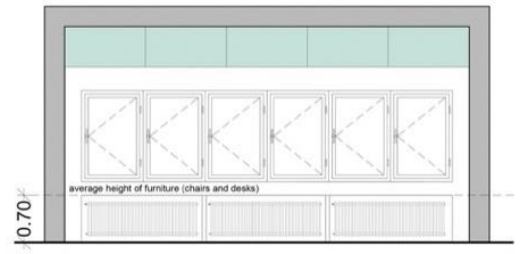

P2

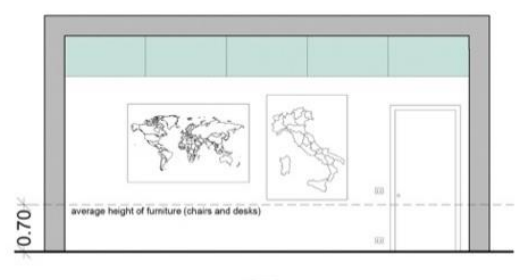

P4

Figure 12. Configuration of the typical classroom with the "cornice" part on all four walls (in light grey) and with the "acoustic shapes" part only on the P3 wall (in a darker grey).

As mentioned before, students themselves (under the guidance of their teachers) can design and manufacture the "acoustic shapes" part of the system, using their imagination and creativity. This part consists in the application on the free wall (P3 in Figure 12) of a variety of compositions obtained through the combination of panels with different geometrical shapes and sizes.

The location of the "acoustic shapes" part only on the wall behind the students is justified also by some studies and regulations, according to which it is advisable to locate most of the absorbing surfaces at a high level and preferably on the back wall facing the teacher [97].

For this part of the acoustic correction system, a specific assembly kit was designed. This kit is inspired by Tangram, the ancient Chinese puzzle consisting of seven pieces (one square, one parallelogram and five right triangles) which, placed side by side and without overlapping, can create, through the imaginative capacity of the player, a great number of different figures; see Figure 13.

In order to extend the range of possible figures without affecting the simplicity of the kit and of its parts, a set with four different elements was devised; see Figure 14.

The elements of the set are modules of a "basic" rectangular $30 \times 60 \times 5 \mathrm{~cm}$ element, as in Figure 14, and are obtained by dividing it (a) into two pieces, both longitudinally, thus obtaining a $30 \times 30 \times 5 \mathrm{~cm}$ square element, and (b) diagonally, which results in two equal right scalene triangles (element $\mathrm{a}_{1}$ ). Dividing the square panel along the diagonal results in two right isosceles triangles (element $b_{1}$ ). This modularity facilitates the production and packing of the kit's elements, thus favouring logistic and transport operations. 

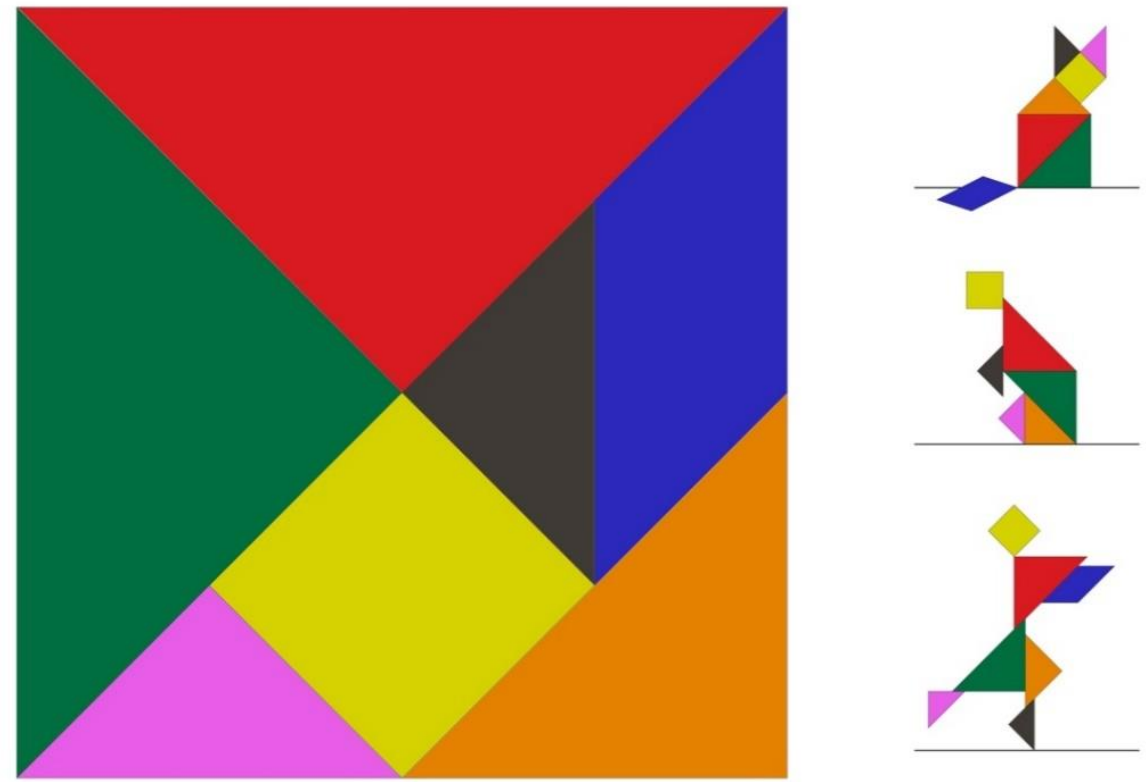

Figure 13. Tangram and some examples of shapes that can be made using its 7 pieces.

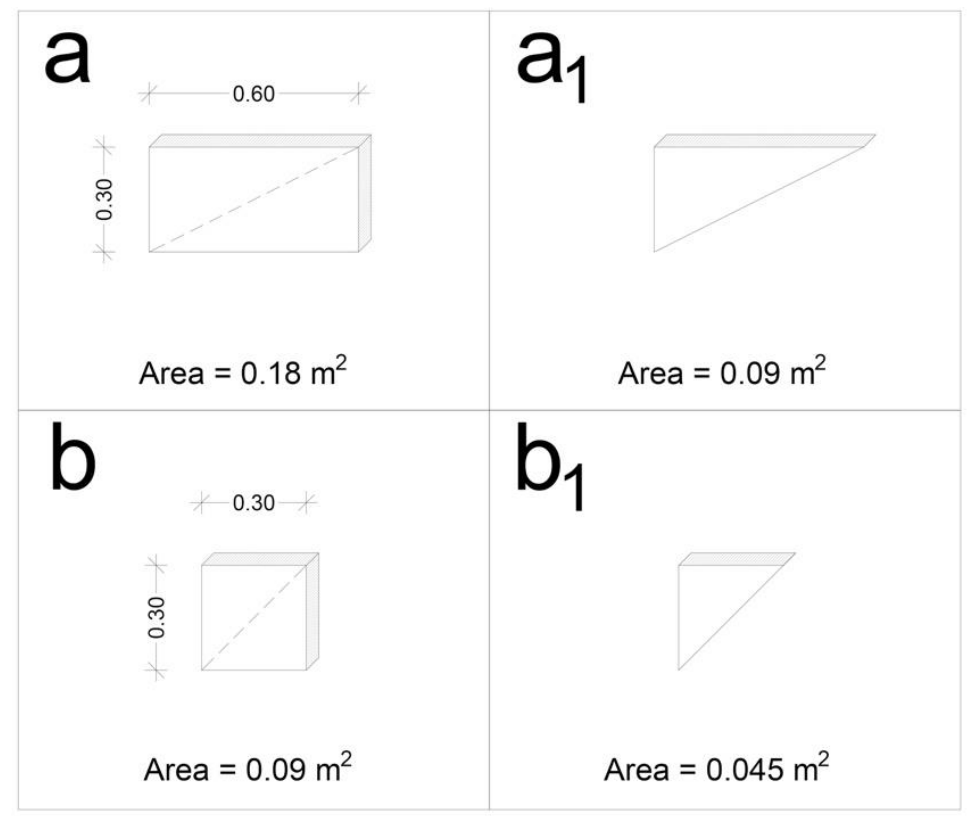

Figure 14. Set of 4 elements for creating the "acoustic shapes".

Although the panels with parallel sides (square and rectangle) are easier to produce, the kit also includes triangular panels. The use of triangular elements, in fact, greatly expands the range of the possible figures (as shown by the Tangram puzzle). Naturally, teachers can also make further triangular shapes in the classroom, cutting square and rectangular panels along the diagonal by a common utility cutter. Moreover, in order to increase the educational value of acoustic shapes, the panels (in particular, the square panel (b)), can be easily shaped to obtain isosceles triangles, hexagons or octagons, with whom the geometric developments of complex solids can be realized, such as tetrahedra, octahedron and icosahedron, to bring students closer to the knowledge of solid geometry. Polystyrene fibre panels are well suited to this purpose, since they ensure a clear cut and do not generate any relevant fallout of particles. 
In order to raise their communicative capacity, kit elements could be coloured by the students or clad in fabric or micro-perforated sheets (equally soft and light) in such a way as to design on the surface symbols, letters, drawings or textures.

In order for acoustic shapes to be easily made by the students and modifiable through time, two solutions for hanging them on the wall have been envisaged: (1) with a "hook and loop" fastener (such as Velcro); or (2) with the use of magnetic elements. As a result of the stress caused by the ripping action, the hook and loop system probably provides less durability than the option with magnetic elements.

In both fastening solutions, the panels would be affixed to horizontal strips (made of fabric in the case of the hook and loop tape and metallic in the case of magnetic elements) placed at intervals of around $15 \mathrm{~cm}$ from one another; see Figure 15.

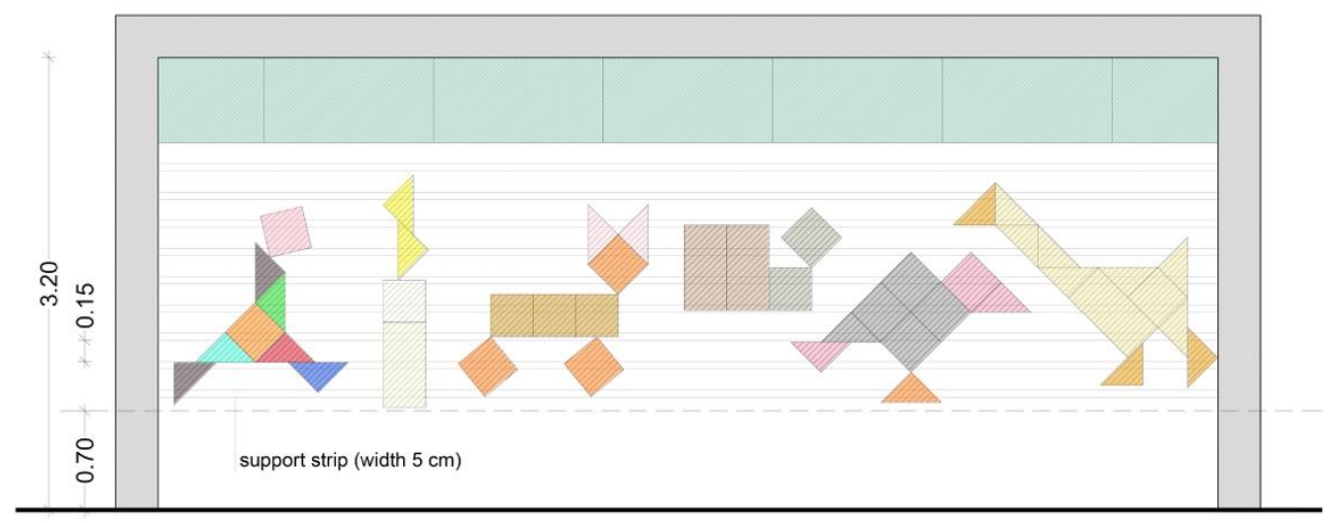

Figure 15. Example of an "acoustic shapes" layout.

The support strips should be attached to the wall preferably by specialised personnel through either sticking or mechanical fastening. Once the support strips have been completed, students and teachers can proceed with the project, creating and fastening the "acoustic shapes"; see Figures 16-18.
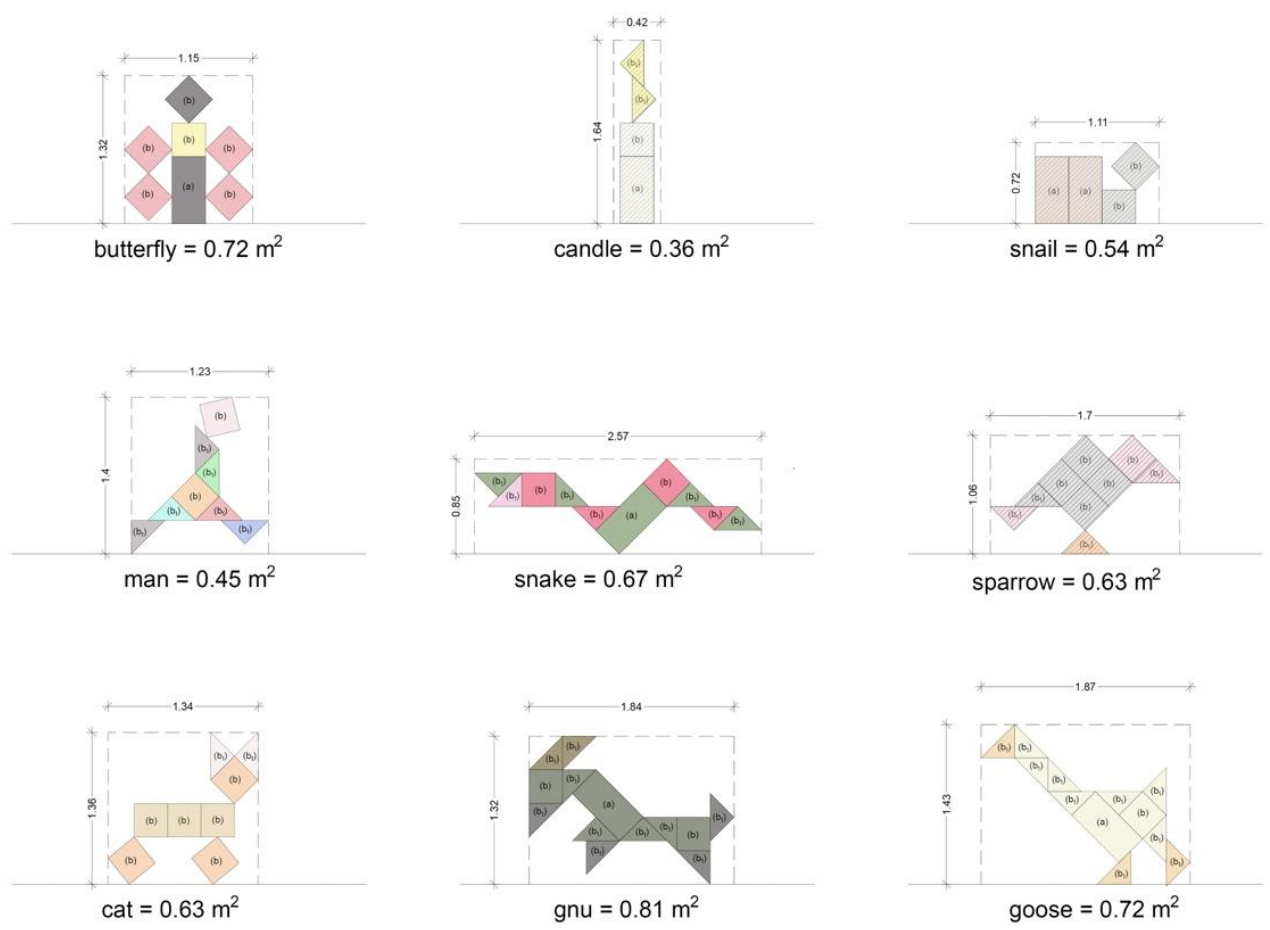

Figure 16. Examples of some figures that can be created with the kit elements. 

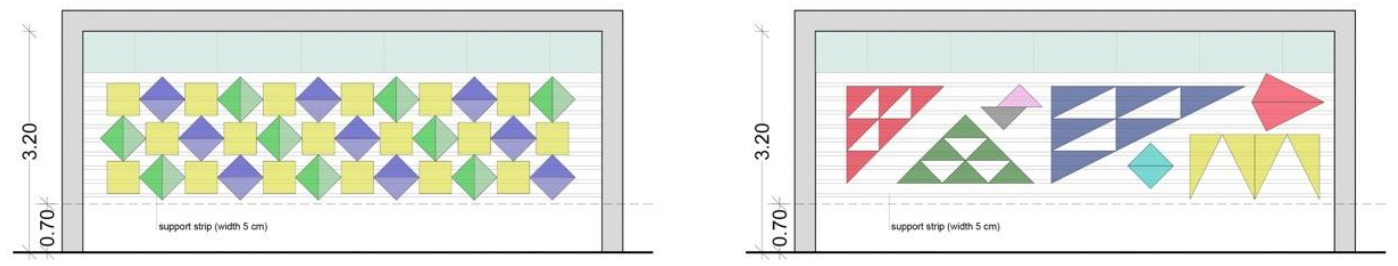

Figure 17. Two possible wall configurations using "acoustic shapes".
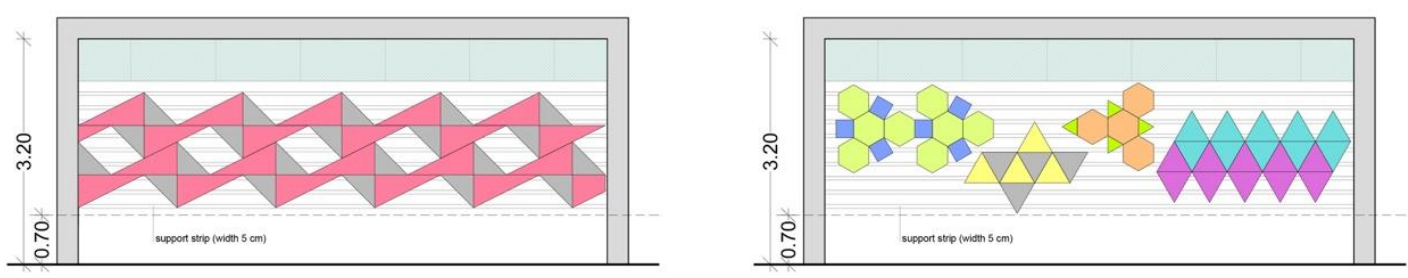

Figure 18. Two possible wall configurations using "acoustic shapes" shaped by the teachers and coloured by the students.

It is important that both the cornice and the acoustic shapes are mounted simultaneously so as to emphasize for children and teachers the effect of the reduction of sound reverberation.

With the purpose of providing guidance and stimulating the curiosity and creativity of students, the assembly kit should be accompanied by an instruction manual, which includes: (1) some examples of figures that can be created, (2) the necessary instructions for attaching the panels to the support strips and (3) a description of the acoustic benefits that can be obtained.

Whereas the "cornice" sound-absorbing surface, once it has been placed, remains constant through time, the "acoustic shapes", thanks to their "reversible" fastening system, can be modified at will whenever new figures or shapes are desired.

The variable design surface can be calculated by subtracting from the desired sound-absorbing surface $\left(20 \mathrm{~m}^{2}\right.$, in the case of the typical classroom) the fixed component of the system (the "cornice" part, which, in the case of the typical classroom, is equal to $16 \mathrm{~m}^{2}$ ). The "assembly kit" will therefore include a pre-determined amount of sound-absorbing elements necessary for covering a total surface of $4 \mathrm{~m}^{2}$.

In order to ensure adequate versatility and freedom of composition, a kit including a total of 60 pieces has been devised, containing:

- Four $30 \times 60 \times 5 \mathrm{~cm}$ rectangular elements (a) $\left(0.72 \mathrm{~m}^{2}\right)$;

- Four $30 \times 60 \times 5 \mathrm{~cm}$ triangular elements $\left(\mathrm{a}_{1}\right)\left(0.36 \mathrm{~m}^{2}\right)$;

- Twenty $30 \times 30 \times 5 \mathrm{~cm}$ square elements (b) $\left(1.8 \mathrm{~m}^{2}\right)$;

- Thirty-two $30 \times 30 \times 5 \mathrm{~cm}$ triangular elements $\left(\mathrm{b}_{1}\right)\left(1.44 \mathrm{~m}^{2}\right)$.

These quantities refer to the typical classroom and they should be modified in the case of smaller or larger classrooms. Indeed, also considering very large classrooms, the same system composed by a fixed part (the "cornice") and a variable part (the "acoustic shapes") could be applied. For example, a classroom with a volume of $250 \mathrm{~m}^{3}(8 \times 9 \mathrm{~m}$ with a height of $3.5 \mathrm{~m})$ could have a fixed surface (the "cornice") of around $30.5 \mathrm{~m}^{2}$ and a variable part (the "acoustic shapes") of around $7.5 \mathrm{~m}^{2}$.

In addition to the sound-absorbing elements, the kit should include the support strips, the instruction manual with the indications for its assembly and some examples of possible figures and wall compositions to be made by the students. The entire kit for the typical classroom will fit in a $60 \times 60 \times 65 \mathrm{~cm}$ box, making it easy to handle; see Figure 19 . 


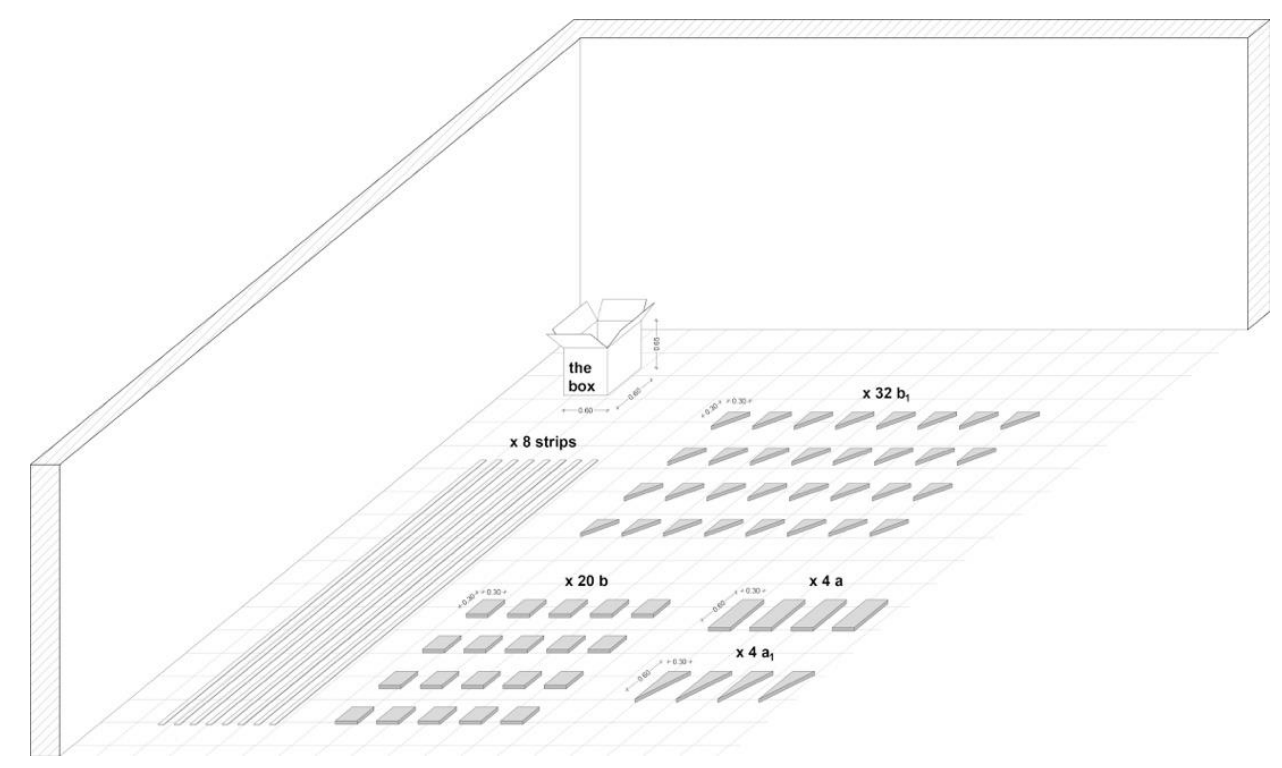

Figure 19. Packaging of the elements included in the assembly kit.

In the case of classrooms significantly smaller or larger than the typical classroom, different kits (labelled "small", "medium" and "large") could be provided.

\section{Discussion}

In his well-known Notes on the Synthesis of Form [100], Christopher Alexander described design activity as a correspondence between two entities: the context, which defines the "problem", and the form, which resolves it. According to Alexander, in order to adequately support and orient the definition of the form (the design choices), a deep knowledge of the context is necessary, through a solid and wide-ranging preliminary research phase, based on the contribution of knowledge derived from both the social and the natural sciences. Only in this way can the "form" aspire and respond to the various physical, physiological, psychological and relational needs of the inhabitants.

Moreover, as regards the indoor environmental quality (IEQ) it is necessary to explore, understand and address the various environmental descriptors of human wellbeing, both those which are measurable and those that are not. Although difficult, it is necessary to accept the challenge of complexity and to go beyond partial or determinist approaches-which, in acoustics, are expressed as decibel-based metrics-so as to tend toward a holistic approach based on the adaptive relationship between human beings and the environment (physical, social, cultural) in which they live [3-5,37,101-105].

This paper focuses on the possibility of "transforming" a traditional acoustic correction intervention into an educational resource, a health factor for the entire classroom group (students and teachers) and an experience of healthy learning [32,106].

The paper highlights not only the importance of the result which can be achieved through the proposed intervention (reduction of reverberation times) in terms of acoustic comfort, but also the "educational" benefits which would derive from the participation of the students in this experience. Understanding salutogenesis in educational terms strengthens in the students the capacity to manage the complexity of their relationships with others and with their surrounding environment.

This approach aims to valorise two aspects of the relationship between salutogenesis and learning. Indeed, while the active participation of the students in the construction of a healthier environment (with better acoustic quality), on the one hand, favours the learning process (better speech understanding), on the other, enabling students to acquire an adaptive coping strategy (proactive, social and meaning-focused) helps them to address discomfort and restore a state of wellbeing [25]. 
The possibility of interacting with their living space and modifying their school environment can lead both students and teachers to a better usage and enjoyment of their place of teaching-learning, thus enhancing to the fullest extent its educational function $[107,108]$.

Finally, in the design of the described system for the acoustic correction of classrooms, a great amount of attention to spatial aspects was paid, with the aim of identifying, together with an adequate technical solution, a versatile and aesthetically pleasing architectural solution.

\section{Future Developments}

The acoustic correction system described still requires an engineering phase. Both the fastening of the "cornice" part and the anchoring of the "acoustic shapes" can be carried out using various methods and materials. These options should be carefully assessed in reference to specific contexts and in accordance with the requirements specified in Table 1.

As for the "acoustic shapes", it is necessary to further study the techniques for the coupling of the sound-absorbing panel with the support strips on the walls.

Methods could also be studied for enhancing the cleanability of the panels and for permitting a greater reversibility of the kit elements (both panels and support strips) once they have reached the end of their life cycle-for example, by facilitating the separation of the various system components.

Additional developments could concern the instruction manual and the packaging. The latter could be used as a template for making the composition of the "acoustic shapes" easier and swifter, as well as to provide support in the cutting of the panels.

A pedagogical strategy to involve the children into the process of improving the acoustics of their classroom could also be investigated. This strategy could be based, for example, on a web application that would advise and instruct the teachers on how to obtain the input data required for the calculation of the required quantity of absorbing material. Assisted by their teacher, children could also carry out a simple measurement of the reverberation time by using an application on a smartphone. Based on these data, the required absorption could be calculated by the application and divided into fixed (the "cornice") and variable parts (the "acoustic shapes").

Finally, in order to understand the overall effectiveness of the system (acoustic improvement and value of the educational experience), it would be necessary to carry out an ex post assessment of the reactions and of the level of satisfaction of the students and teachers with the use of adequate dialogue tools (in-depth interviews, focus groups, etc.) [109].

Author Contributions: The authors (A.L., S.S. and L.V.) laid out the conceptual framework of the paper and contributed equally to edit its final version. All authors have read and agreed to the published version of the manuscript.

Funding: This research was funded by the Savings Bank Foundation of Florence (Fondazione Cassa di Risparmio di Firenze, https://www.fondazionecrfirenze.it/), contract n. 2017/0809, by the Municipality of Florence (www. comune.fi.it) and by Manifattura Maiano spa (www.maiano.it).

Acknowledgments: Authors wish to thank Lucia Bigozzi, Gianfranco Cellai, Giulia Vettori, Arch. Veronica Amodeo and Eng. Fabio Brocchi for their participation in the research. We thank the reviewers for their interesting suggestions which allowed us to improve the quality of the paper.

Conflicts of Interest: The authors declare no conflict of interest. The funders had no role in the design of the study; in the collection, analyses, or interpretation of data; in the writing of the manuscript, or in the decision to publish the results.

\section{References}

1. ISO. 28802:2012, Ergonomics of the Physical Environment-Assessment of Environments by Means of an Environmental Survey Involving Physical Measurements of the Environment and Subjective Responses of People; International Organization for Standardization: Geneva, Switzerland, 2012.

2. Bluyssen, P. Towards New Methods and Ways to Create Healthy and Comfortable Buildings. Build. Environ. 2010, 45, 808-818. [CrossRef]

3. Gibson, J. The Senses Considered as Perceptual Systems, 2nd ed.; Allen and Unwin: London, UK, 1968. 
4. Pallasmaa, J. The Eyes of the Skin, 3rd ed.; John Wiley \& Sons: Somerset, NJ, USA, 2005.

5. Ingold, T. Being Alive: Essays on Movement, Knowledge and Description, 1st ed.; Routledge: Abingdon, UK, 2011.

6. Ulrich, R.S. View through a window may influence recovery from surgery. Science 1984, 224, 420-421. [CrossRef] [PubMed]

7. Kang, J. Urban Sound Environment, 1st ed.; Taylor \& Francis Incorporating Spon: London, UK, 2006.

8. Diener, E.; Wirtz, D.; Tov, W.; Kim-Prieto, C.; Choi, D.; Oishi, S.; Diener, R.B. New measures of well-being: Flourishing and positive and negative feelings. Soc. Indic. Res. 2010, 97, 143-156. [CrossRef]

9. Dodge, R.; Daly, A.; Huyton, I.; Sanders, L. The challenge of defining wellbeing. Int. J. Wellbeing 2012, 2, 222-235. [CrossRef]

10. Huppert, F.; So, T. Flourishing across Europe: Application of a new conceptual framework for defining well-being. Soc. Indic. Res. 2013, 110, 837-861. [CrossRef]

11. Wierzbicka, A.; Pedersen, E.; Persson, R.; Nordquist, B.; Stålne, K.; Gao, C.; Harderup, L.; Borell, J.; Caltenco, H.; Ness, B.; et al. Healthy indoor environments: The need for a holistic approach. Int. J. Environ. Res. Publ. Health 2018, 15, 1874. [CrossRef] [PubMed]

12. Hanc, M.; McAndrew, C.; Ucci, M. Conceptual approaches to wellbeing in buildings: A scoping review. Build. Res. Inf. 2019, 47,767-783. [CrossRef]

13. Rohde, L.; Larsen, T.S.; Jensen, R.L.; Larsen, O.K. Framing holistic indoor environment: Definitions of comfort, health and well-being. Indoor Built. Environ. 2019, 29, 1118-1136. [CrossRef]

14. Torresin, S.; Aletta, F.; Babich, F.; Bourdeau, E.; Harvie-Clark, J.; Kang, J.; Lavia, L.; Radicchi, A.; Albatici, R. Acoustics for Supportive and Healthy Buildings: Emerging Themes on Indoor Soundscape Research. Sustainability 2020, 12, 6054. [CrossRef]

15. Zagreus, L.; Huizenga, C.; Arens, E.; Lehrer, D. Listening to the occupants: A Web-based indoor environmental quality survey Practical implications. Indoor Air 2004, 14 (Suppl. 8), 65-74. [CrossRef]

16. Zeisel, J. Inquiry by Design: Tools for Environment-Behavior Research, 1st ed.; Cambridge University Press: Cambridge, MA, USA, 1984.

17. Berglund, B.; Nilsson, M.E. On a tool for measuring soundscape quality in urban residential areas. Acta Acust. United Acust. 2006, 92, 938-944.

18. Torresin, S.; Albatici, R.; Aletta, F.; Babich, F.; Kang, J. Assessment methods and factors determining positive indoor soundscapes in residential buildings: A systematic review. Sustainability 2019, 11, 5290. [CrossRef]

19. Stockfelt, T. Sound as an existential necessity. J. Sound Vib. 1991, 151, 367-370. [CrossRef]

20. Gehl, J. Life between Buildings: Using Public Space, 1st ed.; Van Nostrand Reinhold: New York, NY, USA, 1987.

21. Laurìa, A. Human requirement-based design in the cultural dimension of living. In Research among Innovation, Creativity and Design, 1st ed.; Bolici, R., Gambaro, M., Tartaglia, A., Eds.; Firenze University Press: Firenze, Italy, 2012; pp. 409-439.

22. Kang, J.; Aletta, F.; Gjestland, T.T.; Brown, L.A.; Botteldooren, D.; Schulte-Fortkamp, B.; Lercher, P.; van Kamp, I.; Genuit, K.; Fiebig, A.; et al. Ten questions on the soundscapes of the built environment. Build. Environ. 2016, 108, 284-294. [CrossRef]

23. Altomonte, S.; Allen, J.; Bluyssen, P.M.; Brager, G.; Heschong, L.; Loder, A.; Schiavon, S.; Veitch, J.A.; Wang, L.; Wargocki, P. Ten questions concerning well-being in the built environment. Build. Environ. 2020, 180, 106949. [CrossRef]

24. WHO. Ottawa Charter for Health Promotion; WHO: Geneva, Switzerland, 1986.

25. Garista, P. L'ombrello della salutogenesi. per connettere benessere e apprendimento. Rifessioni Sistemiche 2017, 16, 59-70.

26. Lazarus, R.S. Psychological Stress and the Coping Process, 1st ed.; McGraw Hill: New York, NY, USA, 1966.

27. Lazarus, R.S.; Folkman, S. Stress, Appraisal, and Coping, 1st ed.; Springer International Publishing: New York, NY, USA, 1984.

28. Antonovsky, A. Health, Stress and Coping, 1st ed.; Jossey-Bass Publishers: San Francisco, CA, USA, 1979.

29. Antonovsky, A. Unraveling the Mystery of Health, How People Manage Stress and Stay Well, 1st ed.; Jossey-Bass Publishers: San Francisco, CA, USA, 1987.

30. Antonovsky, A. A salutogenic model as a theory to guide health promotion. Health Promot. Int. 1996, 11, 11-18. [CrossRef] 
31. Lawton, M.P. Competence, environmental press, and the adaptation of older people. In Aging and the Environment: Theoretical Approaches; Lawton, M.P., Windley, P.G., Byerts, T.O., Eds.; Springer Publishing Company: New York, NY, USA, 1982; Volume 7, pp. 33-35.

32. Lindström, B.; Eriksson, M. Salutogenesis. J. Epidemiol. Community Health 2005, 59, 440-442. [CrossRef]

33. Mittelmark, M.B.; Sagy, S.; Eriksson, M.; Bauer, G.F.; Pelikan, J.M.; Lindström, B.; Espnes, G.A. The Handbook of Salutogenesis, 1st ed.; Springer International Publishing: New York, NY, USA, 2017.

34. Fänge, A.; Iwarsson, S. Changes in accessibility and usability in housing: An exploration of the housing adaptation process. Occup. Ther. Int. 2005, 12, 44-59. [CrossRef]

35. Fänge, L.; Iwarsson, S. Challenges in the development of strategies for housing adaptation evaluations. Scand. J. Occup. Ther. 2007, 14, 140-149. [CrossRef]

36. Iwarsson, S.; Slaug, B. Housing Enabler-A Method for Rating/Screening and Analyzing Accessibility Problems in Housing. In Manual for the Complete Instrument and Screening Tool, 1st ed.; Veten \& Skapen HB \& Slaug Data Management: Lund, Sweden, 2010.

37. Laurìa, A.; Benesperi, B.; Costa, P.; Valli, F. Designing Autonomy at Home. The ADA Project. In An Interdisciplinary Strategy for Adaptation of the Homes of Disabled Persons, 1st ed.; Firenze University Press: Firenze, Italy, 2019.

38. Gerlach, K.A. Environmental design to counter occupational boredom. J. Archit. Res. 1974, 3, 15-19.

39. Toftum, J. Air movement-Good or bad? Indoor Air 2004, 14 (Suppl. 7), 40-45. [CrossRef] [PubMed]

40. Candido, C.; de Dear, R. From thermal boredom to thermal pleasure: A brief literature review. Ambiente Construido 2012, 12, 81-90. [CrossRef]

41. Cabanac, M. Physiological role of pleasure. Science 1971, 173, 1103-1107. [CrossRef] [PubMed]

42. de Dear, R. Revisiting an Old Hypothesis of Human Thermal Perception: Alliesthesia. Build. Res. Inf. 2011, 39, 108-117. [CrossRef]

43. Parsons, K.C. The effects of gender, acclimation state, the opportunity to adjust clothing and physical disability on requirements for thermal comfort. Energy Build. 2002, 34, 593-599. [CrossRef]

44. Karjalainen, S. Gender differences in thermal comfort and use of thermostats in everyday thermal environments. Build. Environ. 2007, 42, 1594-1603. [CrossRef]

45. ASHRAE. Standard 55-Thermal Environmental Conditions for Human Occupancy, 3rd ed.; ASHRAE: Atlanta, GA, USA, 2013.

46. Zhe, Y.; Lin, B.; Ghahramani, A.; de Dear, R.; He, Y.; Luo, M.; Wang, Z. Individual difference in thermal comfort: A literature review. Build. Environ. 2018, 138, 181-193.

47. Fabbri, K. Thermal comfort evaluation in kindergarten: PMV and PPD measurement through datalogger and questionnaire. Build. Environ. 2013, 68, 202-214. [CrossRef]

48. Soebarto, V.; Zhang, H.; Schiavon, S. A thermal comfort environmental chamber study of older and younger people. Build. Environ. 2019, 155, 1-14. [CrossRef]

49. Fabbri, K.; Gaspari, J.; Vandi, L. Indoor Thermal Comfort of Pregnant Women in Hospital: A Case Study Evidence. Sustainability 2019, 11, 6664. [CrossRef]

50. Mehrabian, A. Public Places and Private Spaces-The Psychology of Work, Play, and Living Environments, 1st ed.; Basic Books Inc. Publisher: New York, NY, USA, 1976.

51. Spagnolo, R. (Ed.) Manuale di Acustica Applicata, 1st ed.; UTET: Torino, Italy, 2001.

52. Rasmussen, B.; Machimbarrena, M. (Eds.) COST Action TU0901-Building acoustics throughout Europe. Volume 1: Towards a common framework in building acoustics throughout Europe; DiScript Preimpresion, S.L.: Madrid, Spain, 2014.

53. Yang, W.; Kang, J. Acoustic comfort evaluation in urban open public spaces. Appl. Acoust. 2005, 66, $211-229$. [CrossRef]

54. Hall, E.T. The Hidden Dimension, 1st ed.; Doubleday: New York, NY, USA, 1966.

55. Martellotta, F. Subjective study of preferred listening conditions in Italian Catholic churches. J. Sound Vib. 2008, 317, 378-399. [CrossRef]

56. Liu, S.; Schiavon, S.; Das, H.P.; Jin, M.; Spanos, C.J. Personal thermal comfort models with wearable sensors. Build. Environ. 2019, 162, 106281. [CrossRef]

57. Basner, M.; Babisch, W.; Davis, A.; Brink, M.; Clark, C.; Janssen, S.; Stansfeld, S. Auditory and non-auditory effects of noise on health. Lancet 2014, 383, 1325-1332. [CrossRef]

58. Wright, S. User involvement in School Building Design. Forum 2004, 46, 41-43. [CrossRef] 
59. Dockrell, J.E.; Shield, B. Children's perceptions of their acoustic environment at school and at home. J. Acoust. Soc. Am. 2004, 115, 6, 2964-2973. [CrossRef]

60. Klatte, M.; Bergström, K.; Lachmann, T. Does noise affect learning? A short review of noise effects on cognitive performance in children. Front. Psychol. 2013, 4, 578. [CrossRef]

61. Connolly, D.M.; Dockrell, J.E.; Shield, B.M.; Conetta, R.; Cox, T.J. Students' perceptions of school acoustics and the impact of noise on teaching and learning in secondary schools: Findings of a questionnaire survey. Energy Procedia 2015, 78, 3114-3119. [CrossRef]

62. Iglehart, F. Speech Perception in Classroom Acoustics by Children with Hearing Loss and Wearing Hearing Aids. Am. J. Audiol. 2020, 29, 6-17. [CrossRef]

63. Klatte, M.; Hellbrück, J.; Seidel, J.; Leistner, P. Effects of classroom acoustics on performance and Well-being in elementart school children: A field study. Environ. Behav. 2010, 42, 659-692. [CrossRef]

64. Astolfi, A.; Puglisi, G.; Murgia, S.; Minelli, G.; Pellerey, F.; Prato, A.; Sacco, T. Influence of Classroom Acoustics on Noise Disturbance and Well-Being for First Graders. Front. Psychol. 2019, 10, 2736. [CrossRef] [PubMed]

65. Bottalico, P.; Astolfi, A. Investigations into vocal doses and parameters pertaining to primary school teachers in classrooms. J. Acoust. Soc. Am. 2012, 131, 2817-2827. [CrossRef] [PubMed]

66. Puglisi, G.E.; Astolfi, A.; Cantor Cutiva, L.C.; Carullo, A. Four-day-follow-up study on the voice monitoring of primary school teachers: Relationships with conversational task and classroom acoustics. J. Acoust. Soc. Am. 2017, 141, 441-452. [CrossRef]

67. Astolfi, A.; Bottalico, P.; Accornero, A.; Garzaro, M.; Nadalin, J.; Giordano, C. Relationship between vocal doses and voice disorders on primary school teachers. In Proceedings of the Ninth European Conference on Noise Control, EuroNoise 2012, Prague, Czech Republic, 10-13 June 2012.

68. Bottalico, P.; Cantor Cutiva, L.C.; Hunter, E.J. Vocal fatigue in virtual acoustics scenarios. J. Acoust. Soc. Am. 2017, 141, 3541. [CrossRef]

69. Bottalico, P.; Astolfi, A.; Hunter, E.J. Teachers' voicing and silence periods during continuous speech in classrooms with different reverberation times. J. Acoust. Soc. Am. 2017, 141, EL26-EL31. [CrossRef]

70. Rudner, M.; Lyberg Åhlander, V.; Brännström, J.; Nirme, J.; Pichora-Fuller, M.K.; Sahlen, B. Listening Comprehension and Listening Effort in the Primary School Classroom. Front. Psychol. 2018, 9. [CrossRef]

71. Clark, H. Building Education: The Role of the Physical Environment in Enhancing Teaching and Research, 1st ed.; Institute of Education, University of London: London, UK, 2002.

72. Annesley, B.; Horne, M.; Cottam, H. Learning Buildings, 1st ed.; School Works Ltd.: London, UK, 2002.

73. Dudek, M. Architecture of Schools: The New Learning Environments, 1st ed.; Architectural Press: Oxford, UK, 2000.

74. Secchi, S.; Bigozzi, L.; Laurìa, A.; Vettori, G.; Vessella, L. School Quality in Classrooms, Relation between Perception of Sounds and School Performance: Survey Aimed at the Design of a Kit to Support the Acoustic Correction of Classrooms; University of Florence: Florence, Italy, 2020.

75. Vettori, G.; Secchi, S.; Bigozzi, L. Performance di memoria di lavoro verbale in differenti condizioni di qualità acustica. In XXVIII Congresso Nazionale AIRIPA; I disturbi dell'apprendimento: Ferrara, Italy; Giunti, O.S.: Firenze, Italy, 2019; pp. 70-71.

76. Bentley, T.; Fairley, C.; Wright, S. Design for Learning: Joined Up Design for Schools, 1st ed.; Demos: London, UK, 2001.

77. Kirby, P.; Bryson, S. Measuring the Magic: Evaluating and Researching Young People's Participation in Public Decision Making, 1st ed.; Carnegie Young Peoples Initiative: London, UK, 2002.

78. Sommer, R.; Olsen, H. The Soft Classroom. Environ. Behav. 1980, 12, 3-16. [CrossRef]

79. Wong, C.Y.; Sommer, R.; Cook, E. The Soft Classroom 17 Years Later. J. Environ. Psychol. 1992, 12, $337-343$. [CrossRef]

80. Moore, G.T.; Lackney, G.A. Educational Facilities for the Twenty-First Century: Research Analysis and Design Patterns, 1st ed.; Center for Architecture and Urban Planning Research Book; University of Wisconsin: Madison, WI, USA, 1994; p. 32.

81. Lackney, J.A. Thirty-Thre Educational Design Principles for Schools as Community Learning Centers, 1st ed.; Mississippi State University, Educational Design Institute: Starkvile, MS, USA, 2000.

82. Graetz, K. The Psychology of Learning Environments. In Learning Spaces, 1st ed.; Oblinger, D., Ed.; Educause: Boulder, CO, USA, 2006; pp. 60-74. 
83. Mitchell, D. What Really Works in Special and Inclusive Education, 1st ed.; Routledge: London, UK; New York, NY, USA, 2007.

84. Department of Education and Employment (DfEE). Schools: Building on Success. In Raising Standards, Promoting Diversity, Achieving Results, 1st ed.; HMSO: Norwich, UK, 2001.

85. Maltinti, C. Evidence Based Design e progettazione inclusiva. Quali prospettive? Form@re Open J. Per La Form. Rete 2013, 13, 68-79.

86. Secchi, S.; Astolfi, A.; Calosso, G.; Casini, D.; Cellai, G.; Scamoni, F.; Scrosati, C.; Shtrepi, L. Effect of outdoor noise and façade sound insulation on indoor acoustic environment of Italian schools. Appl. Acoust. 2017, 126, 120-130. [CrossRef]

87. Secchi, S.; Brambilla, G.; Casini, D.; Cella, G. A Method to Estimate Students' Exposure to Road Traffic Noise Events. Environments 2018, 5, 39. [CrossRef]

88. UNI. Acustica in Edilizia-Classificazione Acustica Delle Unità Immobiliari-Procedura di Valutazione e Verifica in Opera; 11367:2010; UNI: Milano, Italy, 2010.

89. Rasmussen, B.; Brunskog, J.; Hoffmeyer, D. Reverberation time in class rooms-Comparison of regulations and classification criteria in the Nordic countries. In Proceedings of the Joint Baltic-Nordic Acoustics Meeting, Joint Baltic-Nordic Acoustics Meeting 2012, Odense, Denmark, 18-20 June 2012.

90. ISO. Estimation of Acoustic Performance of Buildings from the Performance of Elements-Sound Absorption in Enclosed Spaces; 12354-6:2006; International Organization for Standardization: Geneva, Switzerland, 2006.

91. Amodeo, V. Qualità Acustica in Classe: Studio dei Casi Tipo e Strategia di Intervento. Master's Thesis, Università degli Studi di Firenze, Firenze, Italy, February 2020.

92. Casini, S.; Lunardi, M.; Masci, D.; Torracchi, C.; Romano, R.; Secchi, S. L'uso della fibra di poliestere riciclato per la correzione acustica degli ambienti interni. Eubios 2016, 58, 12-17.

93. Blanco, I.; Ingrao, C.; Siracusa, V. Life-Cycle Assessment in the Polymeric Sector: A Comprehensive Review of Application Experiences on the Italian Scale. Polymers 2020, 12, 1212. [CrossRef] [PubMed]

94. Intini, F.; Kühtz, S. Recycling in buildings: An LCA case study of a thermal insulation panel made of polyester fiber, recycled from post-consumer PET bottles. Int. J. Life Cycle Assess. 2011, 16, 306-315. [CrossRef]

95. Decreto Ministeriale. Norme Tecniche Aggiornate Relative all'edilizia Scolastica, ivi Compresi gli Indici di Funzionalità Didattica, Edilizia ed Urbanistica, da Osservarsi Nella Esecuzione di Opere di Edilizia Scolastica; Its Subsequent Amendments and Additions; Ministero dei Lavori Pubblici: Roma, Italy, 1975.

96. Fausti, P.; Di Bella, A.; Santoni, A.; Scamoni, F.; Secchi, S.; Semprini, G. The Italian classification scheme of buildings-Application to apartments and schools. In Proceedings of the 2020 International Congress on Noise Control Engineering, 49th International Congress and Exposition on Noise Control Engineering, Seoul, Korea, 23-26 August 2020; Jeon, J.Y., Ed.; The Korean Society of Noise and Vibration Engineering: Seoul, Korea, 2020.

97. Acoustics of Schools: A Design Guide; The Institute of Acoustics (IOA); Association of Noise Consultants (ANC): Milton Keynes, UK, 2015.

98. Dyck, J.A. The case for the L-shaped classroom: Does he shape of a classroom affect the quality of the learning that goes inside it? Princ. Mag. 1994, 74, 41-45.

99. Pääkkönen, R.; Vehviläinen, T.; Jokitulppo, J.; Niemi, O.; Nenonen, S.; Vinha, J. Acoustics and new learning environment-A case study. Appl. Acoust. 2016, 100, 74-78. [CrossRef]

100. Alexander, C. Notes on the Synthesis of Form, 1st ed.; Harvard University Press: Boston, MA, USA, 1964.

101. Cole, R.J.; Robinson, J.; Brown, Z.; O'Shea, M. Re-contextualizing the notion of comfort. Build. Res. Inf. 2008, 36, 323-336. [CrossRef]

102. Vischer, J.C. Towards a user-centred theory of the built environment. Build. Res. Inf. 2008, 36, $231-240$. [CrossRef]

103. Rietveld, E.; Kiverstein, J. A Rich Landscape of Affordances. Ecol. Psychol. 2014, 26, 325-352. [CrossRef]

104. O’Brien, W.; Wagner, A.; Schweiker, M.; Mahdavi, A.; Day, J.; Kjærgaard, M.B.; Carlucci, S.; Dong, B.; Tahmasebi, F.; Yan, D.; et al. Introducing IEA EBC Annex 79: Key challenges and opportunities in the field of occupant-centric building design and operation. Build. Environ. 2020, 178, 106738. [CrossRef]

105. Willems, S.; Saelens, D.; Heylighen, A. Comfort requirements versus lived experience: Combining different research approaches to indoor environmental quality. Archit. Sci. Rev. 2020, 63, 316-324. [CrossRef]

106. Lindström, B.; Eriksson, M. From health education to healthy learning: Implementing salutogenesis in educational science. Scand. J. Public Health. 2011, 39 (Suppl. 6), 85-92. [CrossRef] 
107. Heppel, S.; Chapman, C.; Millwood, R.; Constable, M.; Furness, M.J. Building Learning Futures... A Research Project at Ultralab within the CABE/RIBA "Building Futures" Programme; Council for Architecture and the Built Environment: London, UK, 2004.

108. Higgins, S.; Hall, E.; Wall, K.; Woolnera, P.; McCaughey, C. The Impact of School Environments: A Literature Review, 1st ed.; Design Council; University of Newcastle: London, UK, 2005.

109. Patton, M.Q. Qualitative Research E Evaluation Methods: Integrating Theory and Practice, 4th ed.; SAGE Publications: Thousand Oaks, CA, USA, 2014.

Publisher's Note: MDPI stays neutral with regard to jurisdictional claims in published maps and institutional affiliations.

(C) 2020 by the authors. Licensee MDPI, Basel, Switzerland. This article is an open access article distributed under the terms and conditions of the Creative Commons Attribution (CC BY) license (http://creativecommons.org/licenses/by/4.0/). 